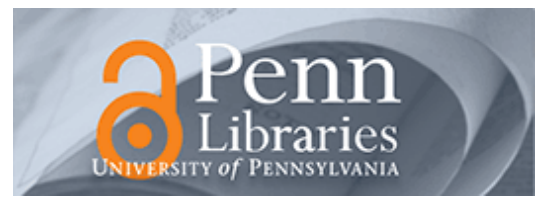

University of Pennsylvania

ScholarlyCommons

Management Papers

Wharton Faculty Research

$5-2010$

\title{
Positioning Knowledge: Schools of Thought and New Knowledge Creation
}

Samuel Phineas Upham

University of Pennsylvania

Lori Rosenkopf

University of Pennsylvania

Lyle H. Ungar

University of Pennsylvania

Follow this and additional works at: https://repository.upenn.edu/mgmt_papers

Part of the Business Administration, Management, and Operations Commons

\section{Recommended Citation}

Upham, S., Rosenkopf, L., \& Ungar, L. H. (2010). Positioning Knowledge: Schools of Thought and New Knowledge Creation. Scientometrics, 83 (2), 555-581. http://dx.doi.org/10.1007/s11192-009-0097-8

This paper is posted at ScholarlyCommons. https://repository.upenn.edu/mgmt_papers/63

For more information, please contact repository@pobox.upenn.edu. 


\title{
Positioning Knowledge: Schools of Thought and New Knowledge Creation
}

\author{
Abstract \\ Cohesive intellectual communities called "schools of thought" can provide powerful benefits to those \\ developing new knowledge, but can also constrain them. We examine how developers of new knowledge \\ position themselves within and between schools of thought, and how this affects their impact. Looking at \\ the micro and macro fields of management publications from 1956 to 2002 with an extensive dataset of \\ $113,000+$ articles from 41 top journals, we explore the dynamics of knowledge positioning for \\ management scholars. We find that it is significantly beneficial for new knowledge to be a part of a \\ school of thought, and that within a school of thought new knowledge has more impact if it is in the \\ intellectual semi-periphery of the school.
}

Keywords

innovation, management, schools of thought, clustering

Disciplines

Business Administration, Management, and Operations 
November, 2005

\title{
Knowledge Positioning:
}

\section{Schools of Thought and New Knowledge Creation}

\author{
Phin Upham \\ The Wharton School \\ Uphams@wharton.upenn.edu \\ Lori Rosenkopf \\ The Wharton School \\ Rosenkopf@wharton.upenn.edu
}

Lyle Ungar

The Wharton School

Ungar@cis.upenn.edu

Working paper 
Abstract: Cohesive knowledge communities called 'schools of thought' can provide powerful benefits to those who develop new knowledge and can also constrain them. We examine how developers of new knowledge position themselves within and between schools of thought and how this in turn affects the impact of their contributions. Looking at the micro and macro fields of management publications from 1956 to 2002 with an extensive dataset of 113,000+ articles from 41 top journals we explore the dynamics of knowledge positioning for management scholars. We find that it is significantly beneficial for new knowledge to be a part of a school of thought and that within a school of thought new knowledge has much more impact if it is in the intellectual semi-periphery of the school rather than at its periphery or center -implying a curvilinear relationship within a school of thought between outside exploration and impact. Specifically, our results show that being a part of a school of thought results in an average increase of 15.03 citations and, within a school of thought, new knowledge positioned in the semiperiphery of the school results, on average, in 2.88 additional citations. We find some conflicting evidence about whether a researcher working in multiple schools of thought results in higher impact.

\section{Introduction:}

Knowledge developers, while creating new knowledge, work in an intellectual and scientific landscape with social structures that shape their actions. In doing so they navigate within, between, and among intellectual "schools of thought" that deeply affect their contributions (1965; Kuhn 1970; Small 2003). Drawing from previous research we develop a strategic understanding of the positioning incentives for researchers in the social science field of management when creating new knowledge. We quantitatively test how the position of researchers within or outside of schools of thought relates to the impact of their contributions. We then test how positioning within schools of thought and a researcher's experience overtime between schools of thought affects performance.

We focus on the epistemic community or mini-paradigm called a 'school of thought.' A school of thought is a socially constructed and informal community of 
researchers building on each other's ideas and sharing similar interests and who consequentially share patterns of citation in their work (Crane 1972; Crane 1980). Research on 'schools of thought' in citation analysis has been limited but very suggestive (Small and Crane 1979; Ennis 1992). While researchers have identified and delineated schools of thought in various fields from management of information science (MIS) to theoretical high energy physics, they have rarely looked at how they function or how they effect new knowledge performance (Crane 1980; Culnan 1987).

The work done within 'schools of thought' has shared intellectual coherency often accompanied by consistency in methodology, and the researchers within them tend to read, reference, and influence each other disproportionately. Seminal work by Thomas Kuhn in The Structure of Scientific Revolutions argues that groups of researchers with a coherent scientific and intellectual world view and a shared set of questions and methodologies are a fundamental part of intellectual thought and rigor (Kuhn 1970). In her description of MIS, Mary Culnan (1986) describes invisible colleges (which we call schools of thought) as inherent to innovative research:

Researchers in any discipline tend to cluster into informal networks, or 'invisible colleges,' which focus on common problems in common ways... The history of the exchanges between members of these subgroups in a discipline describes the intellectual history of the field.

It is perhaps expected that loosely defined groups of like-minded researchers within academic fields will tend to study similar questions with overlapping methodologies (Crane 1989). This holds particularly true for domains in the social sciences where methodology and field-level goals are fragmented and schools of thought are prevalent. .

Jeffrey Pfeffer (1993), discussing the field of Organizational Theory, argues that researchers need a strong paradigm to direct and organize the advancement of knowledge 
through agreed upon goals and vocabulary so that their work can incrementally build on each other. He argues that there is a level of external intellectual "borrowing" from outside ones paradigm causes a lack of coherence in a field. As he puts it, "consensus is a critical precondition for scientific advancement." Nevertheless in the opposite extreme these same forces can socially embed new knowledge builders so that they are structurally disinclined to try to communicate or learn valuable ideas from those outside of their circle - which can lead to intellectual isolation and stagnation.

Generally, schools of thought can be powerful in at least three ways in influencing the process of individual knowledge creation. First, based on conversations with well regarded management scholars, we believe that the generally agreed on boundaries of schools of thought do influence how developers of new knowledge explicitly think about and position themselves within their field - there is an explicit strategic dimension to knowledge positioning (Castro 2001). Secondly, schools of thought are labels for dense social networks that distribute information through personal ties, conferences, conversations, etc.. They deeply influence the knowledge developer's searches, access and ease of information and, in aggregate, an individual author's knowledge stocks and resulting new knowledge contributions (Doreian 1988; Moody 2001). Thirdly, schools of thought represent mental paradigms which unconsciously influence an author's view of the boundaries of their intellectual world (Crane 1980; Pfeffer 1993; Small 2003).

Factors that encourage successful research are of practical as well as scholarly interest to new knowledge developers (Crane 1989). In recent years some management strategists have turned their focus inward and begun to study the field of management as a topic of interest in itself. Earlier studies by management scholars have used citation 
analysis to evaluate areas such as journal prestige (Sharplin and Mabry 1985; Salancik 1986; Extejt and Smith 1990; Gomezmejia and Balkin 1992; Podsakoff 2005), faculty scholarship and institutional productivity (Kirkpatric and Locke, 1992), faculty pay (Gomezmejia and Balkin 1992), and to study the field of management as a cross disciplinary phenomenon (Blackburn 1990).

Some scholars have turned to uncovering the structure of the academic field of management. Rodriguez and Navarro (2004) describe Strategy's development in Strategic Management Journal from 1980 through 2000; Culnan (1990) looks at Organizational Behavior through co-citation techniques to look at the structure of the field; Usdiken and Pasadoes (1995) examine the structural divide between European and North American scholars of Organizational Study. With such self-analysis management authors not only shape research through their studies, but their studies are shaped by the landscape of current research (Meyer 1994).

However the literature, particularly those examining academic research, has not simultaneously examined intellectual structure and performance measures to shed light on the new knowledge development of academic scholars. Nor have previous studies often taken time into account and looked at their fields dynamically. Similarly, while a number of studies in MIS and Bibliometrics delineate fields of scientific and academic study, almost no attention has been given to analyzing whether, and why, being in such a school of thought is beneficial to its members and the advantages and disadvantages of various positions within and among schools of thought, the goal of this study. Indeed, schools of thought contain almost unexamined but powerful social, intellectual, and 
normative mechanisms that influence the impact and direction of knowledge creation (March and Sutton 1997).

To analyze strategies for maximizing effectiveness in an ideological landscape we build on the ideas of positioning theorists (Hotelling 1929; Downs 1957; McGann 2002) and search theorists (March and Simon 1958; Nelson and Winter 1982; Levinthal 1997). Positioning theorists seek to explain the behavior of agents who try to position themselves to appeal to a maximum number of consumers. Search theorists analyze the consequences of local and distant search strategies on outcomes such as innovation. Using these approaches, we show how the implicit incentive structures created by schools of thought affect the impact of new knowledge.

The field of study in this paper, micro- and macro management strategy, has been characterized throughout its history by competing schools of thought taking different and sometimes mutually exclusive points of view of the causal explanations of business phenomena and for identifying the underlying drivers of firm behavior (Mintzberg 1978; Barney 1986). Using a database of $113,000+$ papers from 41 top management journals from 1956-2003, the modern life of management studies, we are able to explore how management scholars can maximize the impact of their publications.

In this paper we have three main objectives. First, we wish to systematically understand the mechanisms by which schools of thought engage and incentivise individual developers of new knowledge. Secondly, we use citation data to explore how schools of thought encourage both local and distant search, integrating the findings of recent innovation literature with our theory. Thirdly, we quantitatively explore the consequences of new knowledge positioning both within and between schools of thought. 
We do so by examining the intellectual organization of the field of management and showing the consequences that the placement of new knowledge has on intellectual impact. We hope to further illuminate the understanding of how knowledge is created, and identify factors that help determine its impact and to raise some potential avenues of study for future researchers.

\section{Theoretical Development}

\section{Positioning}

Hotelling (1929) described a competitive game which was later adapted to explore strategic positioning in ideological space. In the game, two hypothetical newspaper sellers, competing for readers who are distributed evenly along 'Main Street,' can set up their stand anywhere in town. Given that customers will buy the closest newspaper, if one seller were to position himself anywhere but the center of 'Main Street,' the other would position himself a little closer to the center and gain the majority of the customers. Thus both sellers end up converging at the midpoint of 'Main Street.' In this model each player explicitly takes into consideration the moves of other players when acting. This principle in its political variant was applied to the ideological landscape of voters to explain the middle of the road views generally espoused by candidates of major political parties (Downs 1957). Given an even distribution of voters, politicians in a two-party race, in order to appeal to the greatest number of voters, will converge to mainstream positions where they maximize their access to voters in a Nash 
equilibrium. More generally, Downs' work finds that in an intellectual landscape, given Hotelling's assumptions, a central position closest to the greatest number of consumers is optimal.

Further extending Hotelling's theory, Downs (1957) also challenged his assumption of a "normal" distribution of consumers, and other researchers have further extended Hotelling's 'game' by including multiple players or additional consumer (voter) or competitor (candidate) entry, sometimes resulting in different outcomes (Krishna 2001; McGann 2002). The Hotelling-Downs framework has been usefully applied broadly to such areas as marketing and brand positioning (Choi 2004), news coverage (Gasper 2005), and simulations (Marks 2001).

The principles of acting to maximize intellectual proximity to the greatest number of consumers and of a dynamic strategy which takes others' moves into consideration are a powerful framework when analyzing new knowledge development. The strategic positioning of new knowledge developers explored in this paper resembles a very complex multi-player version of the Hotelling problem - one, however, that differs along two key dimensions. First, we attempt to include a social dimension of schools of thought, with profound consequences to Hotelling's strategic principles. Secondly, in our framework the candidates and the voters are flip sides of the same coin (each producer of new knowledge is also a consumer of new knowledge in our knowledge landscape) simultaneously competing with and supporting each other. While very powerful, we find that the positioning theory model in the context of new knowledge development significantly underestimates the important social aspects of the knowledge landscape. 


\section{Search -- Near and Distant}

The tension between local and distant search has been explored by juxtaposing the strategies of exploration and exploitation (March 1991). Exploration (involving distant search) is an attempt to add value by finding a new opportunity while exploitation (involving local search) involves building on existing resources or knowledge in an attempt to extract value. Search strategies have significant effects on the development and structure of their landscape (Levinthal 1991; Levinthal 1997; Levinthal 1998). In the long-term, exploration does produce benefits but it must be "paid for" by exploitation (Barnett and Sorenson 2002). In the shorter term and from a research perspective, interdisciplinary research - explorative by its very nature - increases the difficulty of publishing papers, training graduate students, or receiving funding for a subject (Birnbaum 1981).

However, since the dichotomy between exploration and exploitation is always operationally dependent on the choice of boundary, the way in which we delineate boundaries will determine whether we see a search as near or distant. A number of recent studies examine the tradeoffs of different search strategies but each defines its relevant boundaries of analysis in different ways. Katila and Ahuja (2002) argue that firms can differentiate themselves by creatively and meaningfully reusing old technology to create new knowledge as well as by finding new technologies to achieve breakthroughs. Nerkar (2003) sees firms successfully choosing between recent, cutting edge knowledge and knowledge that integrates understandings developed across time spans. Rosenkopf and Nerkar (2001) use patent data to argue that exploration by an optical-disk firm that spans organizational boundaries (i.e., technologies unfamiliar to the organization) but not 
technological boundaries has the most impact within the optical disk industry. This study thus differentiates between middle-level exploration and radical distant exploration.

Over all, these researchers find that search patterns have profound effects on knowledge creation. This previous research is tied together by the core idea that when new knowledge is developed, some boundary, internal or external, is extended or challenged.

Although theories of local search often take for granted that there is local and distant knowledge -- what makes knowledge accessible and close or inaccessible and far is left unexplored from an intellectual, psychological and resource point of view. Delineating these boundaries is indeed a complex process. We argue that a key part of this intellectual boundary-shaping in knowledge development can be found in socially constructed schools of thought. We believe that schools of thought are a key factor for new knowledge developers in perceiving information as near or far, and we believe that an appropriate intermediate spanning of boundaries between 'schools of thought' is an important potential driver of knowledge creation. By providing an explanation for why new knowledge is close or far we believe we move towards generalizing and integrating previous research on boundary spanning in knowledge creation.

\section{Hypotheses}

In this section we extend three hypotheses about the relationship between the position of new knowledge within a school of thought and that knowledge's subsequent impact. First, we argue that being part of a school of thought increases intellectual impact. Second, we argue that new knowledge's position within a school affects whether 
its impact crosses school of thought boundaries, and that a position near the semiperiphery of a school of thought (but still within the school) leads to greater overall impact. Third, we argue that over time an author's exploratory tendencies between schools of thought, i.e. whether an knowledge developer tends to explore different paradigms or specialize within a paradigm, will affect the impact of his/her ideas.

Schools of thought are collaborative knowledge communities based around common interest entailing the sharing of information and mutual helping-behavior (Crane 1972). Unlike typical communities which are usually based primarily on geography, institutional affiliation, or professional boundaries schools of thought are based on a shared world view.

Schools of thought create mechanisms of at least three kinds which keep members of a school of thought at arms length from other schools, rewarding members and punishing those who are not members. First, a school of thought can create a "private language" (Kripke 1984), phrases, or words which are opaque or unfamiliar to those 'outside' the school or a set of methodologies common to the school. As Lodahl and Gordon (1972) put it, "high consensus... provides an acceptable and shared vocabulary for discussing the content of the field." Often the vocabulary, the methods, and even the ways of framing problems are specific to a field and difficult to replicate by an outsider without significant investment. Second, a school can become detached from other areas of the world by structuring the incentives of their domain through emotional, formal, or reputation based mechanisms to maintain commitment to their world view (Merton 1972). Third, a world view or paradigm can be created that makes other views 
ideologically incompatible without substantial theoretical revision, thus making it difficult for others to incorporate or combine the school with other schools (Crane 1980).

Researchers studying communities of practice, which share many characteristics with schools of thought, have examined how information on how tasks are done in such communities is shared informally (Wenger 1998; Brown 2000). Brown and Duguid (1991) argue that "the ways people actually work usually differ fundamentally from the ways organizations describe that work in manuals, training programs, organizational charts, and job descriptions." These communities have the interesting property that only insiders can fully understand what is being carried out since no document or set of codified rules exists. Membership in a school of thought comes at a cost, it must be learned through time consuming practice, hard earned reputation, and it is hard to fake.

Being a member of a school of thought can confer significant advantages, by allowing new knowledge developers to embed their ideas in powerful methods, tap well developed shared bases, and gain access to resources and support. ${ }^{1}$ Further, people are especially attentive to their special interests and will tend to read pieces that pertain strongly to them (Birnbaum 1981). Members of a school of thought have a well-versed and receptive audience on which they can build and which allows them to "stand on the shoulders" of each other. Additionally, there are social consequences on being part of a school such as the opportunity for repeated interaction and familiarity which is necessary for reputation, trust and a sense of belonging. Outside of a school of thought new

${ }^{1}$ In a related project Powell, et al. (1996) saw alliances as an "admissions ticket" to an informal network of learning among corporations. More generally, such networks of learning can offer members access to learning, financial support, and intellectual underpinnings that are invaluable. 
knowledge has a harder time finding an audience or building on an intellectual tradition (Birnbaum 1981; Small 1999).

The social and intellectual advantages conferred by schools of thought warp the intellectual landscape, making it less advantageous to be outside a school of thought, even if such central between-cluster positions make sense in a Hotelling positioning framework. While the positioning approach maximizes closeness to a large audience, this "closeness" does not account for the invisible social boundaries of schools of thought which reward those within schools of thought. For these reasons, we do not believe such middle-ground positioning at the "center" of a landscape, the equilibrium according to Hotelling, without taking into consideration schools of thought will be optimal. We believe that creators of new knowledge have a strong incentive to position themselves as a part of a specific school of thought in order to maximize their impact (Birnbaum 1981; Stigler, Stigler et al. 1995).

Hypothesis 1. New knowledge has more impact if it is within a school of thought than if it is not.

Given that new knowledge is part of a school of thought, within it's school of thought it can also be "core" or "periphery" Of that school. New knowledge that is core to its school is consistent with the rest of the school in its sources of ideas; new knowledge which is peripheral draws on knowledge that differs in some significant way, usually by drawing on uncommon knowledge or knowledge from outside of the school of thought. We believe that while new knowledge creators receive benefits from being in a school they can also be constrained by it if they blind themselves to good ideas outside that school. Specifically, we believe successful research usually draws from its own 
school and also a few core ideas one or perhaps two other schools, synthesizing knowledge that is near and distant. In the area of technological innovation, studies have shown that patents which combine technologies from different patent classes tend to have more diverse, and potentially greater, impact (Trajtenberg 1990).

Research in local and distant search suggests that new knowledge which is core to its school of thought is likely to be intellectually embedded within that school and have less impact outside of that school and new knowledge which is located closer to the periphery of its school tends to more explicitly engage ideas meaningful both to its own field as well as audiences beyond its field (McCain 1986; McCain 1987). Even within a school, new knowledge which remains too close to the core ideas of a school and does not search for and use new ideas is less likely to break ground and have innovative impact (Meyer 1989; Fleming 2001; Fleming and Sorenson 2001) and is thus less likely to influence others and receive more high citations by those within its school (Rosenkopf and Nerkar 2001).

At the same time, as we argued in Hypothesis I, new knowledge that is not within a school of thought loses helpful colleagues, methodologies, and world-view and has less impact on future knowledge. This implies a tension between belonging to an knowledge community (being within a school of thought) but still diverging in order to draw from outside that community to introduce new ideas and make fresh combinations and contributions (Uzzi forthcoming).

Network and Small World theorists have emphasized the advantages of networks of association with groups of tightly connected clusters when bridged by boundary spanners. These tight cluster formations allow for the small size and repeated 
interactions that help reputations to develop, and thus also serves as a basis of social capital. When new knowledge is both within a school of thought and also has some connections to other clusters and ideas, both of these advantages coexist and are maintained. In this case, the advantages of closed network structures, including the maintenance of reputation, learning and trust, and the advantages of interaction across groups, including new ideas, variation, and synthesis coexist (Burt, unpublished). Uzzi, et al. (forthcoming) defines the curvilinear middle ground between excessive inbreeding and excessive newness as a 'cradle of creativity.' He draws on Watts' (1999) Small World approach to examine this dynamic and illustrates the potential value of moderate levels of familiarity for developing norms, establishing causality, and refining core competencies as well as the value of new sources for radical innovation and fresh ideas.

Previous findings in search and network theory thus drives the intuition that knowledge developed with centrality to a school of thought will tend to have impact largely on that school only while knowledge developed with a peripheral relationship to a school tends to be accessible and influential to both those in the school and to those beyond that school. This would imply that a position toward the periphery of a school, straddling more than one field or reaching beyond one's field would draw a larger audience for new knowledge and receive more overall citations. Such boundary spanning research potentially draws in fresh, interesting outside work into a school, which would potentially result in more impact within one's school as well.

Hypothesis 2. A position toward the intellectual semi-periphery of a school of thought results in greater new knowledge impact. 
We now wish to take into consideration not only the characteristics of the new knowledge but the exploratory tendencies of creators of new knowledge as well. Over time a researcher has a tendency to explore a diversity of knowledge domains or to focus on one knowledge domain. For example, in the field of economics, Oliver Williamson has published most of his works in one school of thought - transaction-cost economics (Williamson 1975; Williamson 1979) - and he is intellectually central to that school.

At the same time, some great new knowledge producers systematically publish works in different fields and are enormously and broadly influential. James March, a peripatetic management scholar who studies organizations, for example, also publishes widely between schools of thought including decision theory, organizational learning and adaptation (March and Simon 1958; March and Shapira 1987; March 1991).

Ron Burt argues that there are theory developers who focus on deepening and refining theory within one field and theory synthesizers who span organizational and knowledge boundaries to combine knowledge in fresh and innovative ways (Burt unpublished). Researchers have examined new knowledge from an author perspective to argue, for example, that author's geographic location and partner prestige affects impact (Gittelman 2003 draft), tenure evaluation (Garfield 1983), and readership (Siggelkow 2001 draft).

The advantages of remaining within a community are well-established in network theory - trust, reputation, and learning, among other social and intellectual benefits, were discussed previously. Further, learning the norms and knowledge structure of a school is an investment that may have to be paid again if one changes schools. Simultaneously, from the perspective of influence of ideas, one could argue that remaining in school of 
thought may cause redundancy in the impact of new knowledge, whereas a specific idea can be made new many times if transported to different fields (Amir 1985).

In evolutionary economics the idea of 'local search,' or search where there is high familiarity, expertise, or current knowledge, is seen as fundamental to developing core competencies and leveraging strengths (Nelson and Winter 1982). The implication is that local search reinforces and develops an area of expertise. A potential downside, on the other hand, of concentrated local search is that an agent can get stranded on 'local peaks' by adopting a strategy that is best according to local searches but is sub-optimal from the perspective of a broader context (March and Simon 1958; Nelson and Winter 1982; Levinthal and Warglien 1999).

New knowledge developed without fresh inputs and without looking further than itself would be in danger of missing important insights, or as Rosenkopf and Nerkar (2001) put it, "the focus that sustains such first order competence can lead firms to develop 'core rigidities' or fall into 'competence traps." For an innovator, the tendency to explore numerous schools of thought seriously, thus helping him/her to avoid falling into such competency traps by interacting with a broad array of knowledge, is demonstrated by exploring and contributing new knowledge in multiple fields. Francis Crick, known for his work on the structure of DNA, seems to believe such theory hopping is essential for creative insight when he argues that some people "have one big bright beautiful idea that they can never abandon. Professional [scientists] know that they have to produce theory after theory before they are likely to hit the jackpot. The very process of abandoning one theory for another gives them a degree of critical detachment that is almost essential if they are to succeed." 
Serious interaction with multiple schools of thought may help to expose a new knowledge producer to ideas that can be synthesized to bridge a structural hole by transporting an idea from an area where it is recognized to another where it is not. Burt (unpublished) argues that heterogeneity between communities is often greater than within them, and so, where new ideas and diversity are valued, boundary spanners can often learn more by moving between or bridging communities than by remaining within them. At the same time, knowledge developers who fail to interact seriously and repeatedly with a school will not gain the full benefits that such an intellectual and social community can provide while sacrificing the learning cost of entry.

We believe that the interests and history of an author, whether eclectic or focused, make a difference in his impact and readership. We find that two strong and competing hypotheses are supported by existing theory. On one hand an author who publishes widely and is involved in the intellectual pursuit of multiple areas lends himself in his eclectic pursuits to the benefits of knowledge combination and thus gains the advantages of synthesizing between schools of thought (Fleming 2001). On the other hand depth of expertise lends itself to more incremental new knowledge production, gaining the advantages of a closed cluster, and perhaps focusing on one area can be more beneficial to a new knowledge creator (Birnbaum 1981).

Hypothesis 3a: Creators of new knowledge who actively engage in multiple schools of thought, over time, have greater impact.

Hypothesis 3b: Creators of new knowledge who concentrate on one or few schools of thought, over time, have greater impact. 
Central to our essay is the idea that new knowledge development is often a result of the constant dynamic tension within the area of a school of thought between the search for synthesis - i.e, recombination, introducing new ideas - and specialization - i.e. developing the world view of the field, deepening the core methods or proposition of a paradigm - and moreover that scholars face strategic choices in positioning themselves within and among schools of thought.

\section{Methods}

\section{Clustering}

Co-citation analysis has been used to systematically map and examine the network structures of research papers or patents since Small and Griffith introduced the first computerized method to accomplish this in the 1970's. Early on, Small and Crane (1979) worked to use large scale clustering techniques to isolate and identify the structure of scientific disciplines. They thus matched a potent methodology with a coherent intellectual explanation for the "clusters" which were observed by Small and Griffith during earlier research.

Since then increasingly sophisticated methods have been developed in diverse fields to cluster and analyze high-dimensional similarities (Popescul 2000; Pantel 2002; Kandylas 2005). To find similar clusters within out data in this paper we have drawn from advances in internet search and genetic data mining to construct a clustering methodology called StrEMer that is substantially faster and of comparable quality to past 
search and mining methods for estimating high-dimensional similarity clusters and takes into consideration our theoretical model for schools of thought.

Our criteria were demanding and not met by existing methods. First, we needed a methodology which allowed us to take into account how clusters changed over time since we wanted to look at data over decades. Second we needed a methodology which allowed for a substantial portion of our data to not belong to a cluster since our theoretical framework saw only a portion of new knowledge as belonging to cohesive intellectual clusters. Third, we wanted our framework to include as few arbitrary parameters as possible, letting the data find its own structure. Lastly, without sacrificing accuracy, we wanted our approach to handle extremely large and high-dimensional datasets as efficient and elegant as possible.

Most current popular clustering programs in computer science search and genetic data mining assume clusters over time are static (Popescul 2000) - that is, that all clusters exist at the beginning and end of the time period under consideration and that no new ones are formed in the interim. This is a tolerable simplifying assumption for short periods in stable environments but more troubling when made for data over time in a dynamic environment where we must consider emerging clusters, merging clusters, and dying clusters. To address this we build in an iterated "overlapping" clustering methodology into our algorithm which re-clusters in overlapping 10 year blocks, stepping forward by one year at a time. Therefore the elements in year 1990 would be clustered based on only the elements in years 1980 to 1990 and papers in year 1991 would be clustered based only on years 1981 to 1991 and so on. Thus, the cluster structure of the data in 1975 can be very different from that of 1995. This allows for new clusters to be 
created and for existing clusters to merge or wither away while the overlapping 10 year time span enforces some continuity on the clusters over time. This reclustering strategy, while it helps capture the dynamic and evolving nature of clusters, does make the clusters harder to visualize through time.

Our clustering problem can be cast as a mixture model in which there are a large number of fairly tight, but possibly overlapping "content clusters" and a "background" of items that do not fit into any of the tighter clusters. We believe this is essential since we believe clusters exist only where cohesive intellectual and social communities do, not everywhere or always. The clustering by committee approach (CBC) allows for background clusters but does not have a clear criterion being optimized and overparameterizes the algorithm for our purposes (Pantel 2002; Kandylas 2005).

Further, unlike less efficient iterated programs such as kmeans and expected maximization (EM) algorithms, our StrEMer approach allows us to set criteria which give bounds on the error of single pass algorithms. In this way it is similar to the streaming clustering approach (Guha 2003), though it uses less restrictive assumptions (Kandylas 2005).

As with standard clustering approaches, our clustering algorithm maximizes the coherence of the clusters as specified by an objective function measure. Objects to be clustered are initially assigned to clusters by a random procedure and maximization is achieved by reassigning each object to the existing cluster with the most similar centroid (which is the sum of the similarity of the objects in a cluster). The whole process is repeated until the objective function cannot be substantially improved. Essentially our method plots citation (network) structure in high-dimensional space and uses the 
objective function to minimize the distance from nearest centroid for all papers simultaneously. Distance represents the angle between the vector representing the paper and the centroid of the cluster it is placed in.

Our StrEMer program accomplishes clustering in three steps (repeated when doing iterated "overlapping" clustering). In Step I, we make a single pass over the data and construct several rough clusters. In Step II, we get a collection of high quality clusters, called committees, based on the clusters we get in Step I. These committees are tight and not similar to each other, which mean high inter-group similarity and low intragroup similarity. In Step III, each element is either assigned to its most similar clusters, or added to the residue list if it is not similar enough to any cluster.

See Appendix A for details and pseudo-code of the clustering methodology we developed and implemented to cluster this data.

\section{Data}

In this paper we examine micro and macro management scholarship - a fast moving, relatively young, and highly fragmented academic field generally taught in business schools which is known for its diversity of ideas and its vigorous schools of thought (Abrahamson 1996; Meyer 1999). To select our data we began with previous rankings of journals in management. An early contributor to ranking management journals was Coe (1969) who established a list of 15 of the most highly respected management journals and, more recently through interviews with management department chairpersons (Coe and Weinstock 1984) added 7 more journals to the list. 
Sharplin and Mabry (1985) developed a weighted measure of the top 10 leading management journals by calculating a "citation impact efficiency" metric which measures the "number of citations per 10,000 words published annually in either Administrative Science Quarterly or the Academy of Management Journal." Podsakoff, et al. (2005) used previous lists to construct a list of the journals that had the most influence today, resulting in a list of 28 journals, including some added as top specialty journals. This study found that between 1981 and 1999 the top 7 journals in management received 61\% of citations and the top 14 journals received $82 \%$ of citations. There is evidence that methods such as co-citation and clustering do in fact overlap heavily with experts' intuition about the field's boundaries (Lenk 1983).

Others since Sharplin and Mabry have refined the methods and lists as the field of strategy has evolved and grown. One method used by Johnson and Podsakoff (1994) to generate a core list from these disparate (and highly overlapping) lists is to include any journal that is counted by more than one of these lists, excluding some of the ad hoc specialty journals added by Podsakoff (Podsakoff 2005). Following this strategy we found 41 core journals in management (see Table 2).

Accessing the Thomson ISI database we have collected complete sets of all articles and their citations for all of journals since 1956. This list of 41 journals includes within the field of management both the macro (which is heavily influenced by Economics and Sociology) and the micro (which is heavily influenced by Psychology) specialties (See Table 1). Every paper in the ISI database since 1956 published in these journals yields a total of 113,014 papers for analysis, the most complete database in this 
area compiled, to our knowledge. The papers include $2+$ million citations in the bibliographies of these articles and $1.5+$ million citations made to these articles.

Bibliometrics, or the quantitative study of bibliography, uses as its unit of analysis the citations made from a published piece of work to other published pieces of work. This methodology is attractive for its impersonality, objectivity, replicability and scalability (Culnan 1986). Bibliometric analysis generally relies on the assumption that citations are a good proxy for influence. Similarly, almost all studies using patents use patent citation as a proxy for patent success (Trajtenberg 1990). In paper-citation work it is commonly assumed that a citation in a specific piece of work indicates intellectual influence on the published work and value to the citing author (Small 1978). This may not always be the case, though, as a well-known citation may be used simply to "represent" a point of view or citations may be made for social reasons. The rigors of the review process and the well-documented correlation between citations and other measures of influence however lead us to believe that citation metrics are at least a useful proxy for influence (Bayer and Folger 1966; Cole and Cole 1967; Osareh 1996). Table 1 and 2 summarize our data.

Insert Table 1

Insert Table 2 


\section{Variables}

Total Citations - For our dependent variable we measure the total impact of a paper as the number of citations that a paper has received subsequent to its publication (Exhibit $1 b)$.

Bibliography Size - To control for the increasing number of citations made in papers, we control for the number of entries in a paper's bibliography. As seen in Exhibit 1a, the average bibliography size increased steadily over the time spanned by our data.

Insert Exhibit 1a and $1 \mathrm{~b}$

Year of Publication - We created dummy variables for each year from 1956-2002 and coded them as the number of years elapsed since 1956.

Journal of Publication - Because different journals tend to receive different citation rates due to varying size of readership and journal prestige, we included dummy variables for each of the 41 journals in our data (Table 2 and Exhibit 2). 
Insert Exhibit 2

CoAuthorship (Binary) - We include a binary variable for whether paper has more than one author ( 1 if co-authored, 0 if single author). This helps control for the differences in the process of joint and individual knowledge production. Almost $34 \%$ of the papers in our data are coauthored.

Cluster (Binary) - This binary variable is coded 1 if the paper is in a cluster (representing a "school of thought") and 0 if the paper is not in a cluster. A little over half of our papers did not belong to any cluster (Table 5).

Distance - A paper is central to its cluster when its citation structure is very similar to the mean of the citation structure of all papers in its cluster (the centroid). Papers which are typical of their clusters will have small distances. Papers which differ from the rest of the group by citing outside sources or by citing uncommonly cited papers will have larger distances. We measure distance as the angle $v$ of the vector representations between the citation structure of a paper and the centroid if its cluster (Exhibit 3).

Insert Exhibit 3 
Because clusters are generated with data from the year of the paper and the 9 previous years, $\mathrm{t}^{(-10)}$ to $\mathrm{t}^{(0)}$, distance represents the centrality of the paper to its cluster historically at the time of publication not the centrality of the paper after publication. ${ }^{2}$ We also include a second order effect for distance to capture curvilinearity.

Diversity of Publications - In order to find a proxy for an author's more general tendency to seek a diversity of knowledge and viewpoints we count the number of clusters an author has published in throughout our dataset. We believe this will give an estimate of an author's tendency to stay in a school of thought or move between schools of thought. We use an entropy or diversity measure (O'Reilly 1998; Teachman 1980; Cumming 2004) to estimate this which is defined as:

$$
H=-\sum_{i=1}^{20}\left[p_{i} \cdot \ln \left(p_{i}\right)\right]
$$

where $p$ is the probability that you are in state $i$. For papers with multiple authors we average their diversity measures.

Total Number of Papers Published -A count of the total number of publications an author has, which is potentially correlated with the Diversity of Publications). For papers with multiple authors we sum their publication counts.

Insert Table 3

\footnotetext{
${ }^{2}$ Reclusterings using data for 5 years after publication $\mathrm{t}(0)$ to $\mathrm{t}(5)$ and for the ten years around the publication $\mathrm{t}(-5)$ to $\mathrm{t}(5)$ yielded comparable similar distance measures, implying that cluster centrality changes gradually.
} 
Analysis

\section{Regressions}

The data used for our analyses are non-negative counts of the number of forward citations for papers published in 41 journals covering both micro and macro management (sometimes called organizational behavior and strategy, respectively). As with previous measures (Small and Crane 1979; Morris, DeYong et al. 2002; Ramos-Rodriguez and Ruiz-Navarro 2004) of publication citation counts, the data exhibit a variance in the number of citations larger than would be expected from a Poisson distribution. We considered using a simple negative binomial (NB) model to account for the excess variance (Huasman, Hall, and Griliches, 1984); however, the numerous zero counts in our data further indicate that a zero-inflated negative binomial regression (ZINBR) model would outperform the NB model (see Exhibit 4). The use of two-stage ZINBR models is helpful when there may be a distinct process influencing the occurrence of a proportion of data points with the value of zero. ${ }^{3}$

To statistically verify our intuition based model selection we formally tested for over-dispersion with a Likelihood Ratio test and excess zero counts with a Vuong test. The results confirmed that the ZINBR is the best model for our data. To further account

\footnotetext{
${ }^{3}$ We anticipate that numerous papers will not be cited for structural reasons, including article type, journal, and bibliography characteristics. Other papers in our database received no citations for the time period covered simply due to chance. There are papers that are cited frequently, leading to over-dispersion in our dataset.
} 
for possible uncaptured heteroskedasticity in our models we report significance using Huber-White standard errors.

Insert Exhibit 4:

\section{Models}

Formally, our model is defined as:

$$
\begin{aligned}
& \operatorname{Pr}(y=0)=p+(1-p)\left(1+\frac{\lambda}{\alpha}\right)^{-\alpha} \\
& \operatorname{Pr}(y>0)=(1-p) \frac{\Gamma(y+\alpha)}{y ! \Gamma(\alpha)}\left(1+\frac{\lambda}{\alpha}\right)^{-\alpha}\left(1+\frac{\alpha}{\lambda}\right)^{-y}
\end{aligned}
$$

where $p$, the probability of a structural zero count, and $\lambda$ are modeled as:

$$
\begin{aligned}
& \ln \left(\frac{p}{1-p}\right)=c_{p}+a_{1} v_{1}+a_{2} v_{2}+\ldots \quad \text { (the zero-inflation portion of the model) } \\
& \ln (\lambda)=c_{\lambda}+b_{1} w_{1}+b_{2} w_{2}+\ldots
\end{aligned}
$$

where $v$ and $w$ are our independent variables, $a$ and $b$ are the corresponding regression coefficients, and the $c$ 's are our regression constants (intercepts). Here $v$ and $w$ are labeled differently though they coincide in our models. The over-dispersion parameter $\alpha$ is determined by the iterative maximum-likelihood procedure used to fit the model.

Thus, the predicted mean number of citations for a paper, given it's characteristics, is $\lambda \cdot(1-p)$ [note this is independent of $\alpha$ ]. Using our formulations for $p$ and $\lambda$ from above and taking natural logarithms this becomes 


$$
\begin{aligned}
& \ln (\lambda \cdot(1-p))=-\left(c_{p}+a_{1} v_{1}+a_{2} v_{2}+\ldots\right)+\ln (p)+\left(c_{\lambda}+b_{1} w_{1}+b_{2} w_{2}+\ldots\right) \\
& \lambda \cdot(1-p)=\frac{\exp \left(c_{\lambda}+b_{1} w_{1}+b_{2} w_{2}+\ldots\right)}{1+\exp \left(c_{p}+a_{1} v_{1}+a_{2} v_{2}+\ldots\right)}
\end{aligned}
$$

This formulation clearly displays the difficulty of interpreting the final regression coefficients. The predicted number of citations depends on the coefficients in both the zero-inflated section as well as the NB section. However, the coefficients do not function in a simple additive manner. To attempt to illustrate the effect sizes of the coefficients we will utilize marginal effects plots to convey the average influence that our explanatory variables exert in the ZINBR model. The zero-inflated portion of the model should be interpreted as predicting the likelihood of a zero count, thus a negative coefficient in this portion indicates a decreased probability of having zero citations. The NB portion of the model can be interpreted in the usual statistical manner. Thus we would expect strongly significant predictors to exhibit opposite signs in the two portions of the ZINB model,

To capture as much of the variance in paper citations as possible before testing our hypotheses, we create a Base Model which predicts a paper's total citations based on external paper and field characteristics without including any cluster-specific information. For the Base Model we construct a ZINB model and include bibliography size, coauthorship, journal and year effects as our explanatory variables. The year effect is necessary because papers that are published earlier tend to have a greater number of citations since they have had more years to accumulate citations that we control for publication year with dummy variables. In predicting the inflated zero counts we utilize these same explanatory variables.

In Model I we build upon our Base Model to explore Hypothesis I, which asks whether a paper benefits from membership in a cluster. To this end we augment our Base 
Model with the binary cluster membership variable identifying whether or not a paper belongs to a cluster.

Model II investigates Hypothesis 2, which argues that a paper at the semiperiphery of its cluster is more likely to be highly cited. We include in the analysis, in addition to the Base Model, the variables distance from center and the squared term of distance from center. We use splines to fully characterize any nonlinear trends. Papers that are not in a cluster are excluded from consideration when fitting this model since they have no meaningful measure for distance. Consequently, the binary cluster membership variable used in Model I is not included in this model.

For Model III we adjust Model I to account for the extent to which an author is benefited or harmed by publishing in many schools of thought (represented by clusters) throughout his or her career. We aim to determine whether individual papers receive more citations if the author has a diverse experience with multiple schools or within few schools of thought in our data - a proxy for an author's more general exploratory tendencies. To do this we include in the analysis a diversity measure to capture author publication diversity in addition to the independent variables included in Model I.

\section{Results}

Our Base Model reveals that we have constructed a sound basis for modeling the number of citations received by papers. The coefficients for all included independent variables are significant $[p<0.001]$ in both the zero-inflation and NB portions of the model as shown in Table 4. To test the effects of our combined year and combined 
journal dummy variables we fit reduced models eliminating each group of dummy variables in turn and compared these models to our full models using Likelihood Ratio tests. The results of these tests confirmed our expectations that both journal of publication and year of publication are significant predictors for all of our models. The results for these tests are given in Table 4.

Insert Exhibit 5:

Insert Table 4:

The addition of an indicator for cluster membership in Model I allows us to test if belonging to a cluster has a positive or negative effect on a paper's total number of citations. Our Model I (see Table 4) includes significant coefficients for cluster membership in both portions which fully supports Hypothesis I Cluster membership, on average, is associated with receiving $15.03^{4}$ more citations, holding all other variables unchanged. Exhibit 6 is a visual representation of the average effect for cluster membership, as seen by the positive slope of the linear fit.

\footnotetext{
${ }^{4} 15.03$ is the slope of the line plotted in Exhibit 6. It is the difference between predicted citation counts for in-cluster papers and non-cluster papers after removing extreme outliers.
} 
Insert Exhibit 6:

As seen in Table 4, the independent variables from our Base Model remain significant and the directions of these coefficients, along with their interpretations, remain the same. Furthermore, there is a strong (inverse) relationship $[p<0.0001]$ between membership in a cluster and receiving zero citations, as seen in Table 5.

Insert Table 5:

When computing Model II we excluded from our consideration all papers that were not assigned to a cluster since they have no meaningful distance measure. Model II includes our variable representing distance, allowing us to test Hypothesis II. Within the NB portion of the model, the significant coefficients for distance squared and for distance indicate a possibly curvilinear relationship between distance and total citations. Within the zero-inflation portion of the model we found that both distance and distance squaredwere non-significant. As seen in Exhibit 7, increasing distance from the core of a cluster is beneficial until distance reaches 0.54 , and beyond this further increase in distance is associated with decreased expected citations. Based on Model II, moving away from the optimal point in the semi-periphery by $\pm \sigma$ (S.D. $=0.1607)$, the number of 
expected citations decreases by $2.88^{5}$, holding other variables constant. The variables held over from our Base Model retain significance in the same direction leaving their interpretations unchanged.

To further characterize the relationship between distance and total citations, particularly because of the skewed nature of papers towards the core of the cluster, we use linear splines to track the effects of distance over smaller intervals. As shown in the upper right corner of Exhibit 7 the quadratic curve is a reasonable parameterization of the relationship though the spline has a plateau in the semi periphery rather than a clear apex.

\section{Insert Exhibit 7:}

Model III allows us to examine diversity of publications as a predictor of total citations. The initial results support our first competing hypothesis which argues that a diverse publication pattern does indeed lead to higher citations. Results are significant $[p<0.01]$ for both the NB and zero-inflation portions of Model III. The positive coefficient in the NB portion indicates that increased diversity in an author's publication pattern, which is associated with the author's interaction with very diverse knowledge and perspectives, is associated with higher citation counts. Similarly in the zero-inflation portion, the more diverse an author's citation pattern, the less likely he or she is to receive zero citations, as indicated by the negative coefficient. As shown in Exhibit 8, on

\footnotetext{
${ }^{5} 2.88$ is the difference in Model II predicted citations at distance $=0.54$ and \pm 1 S.D. (distance $\approx .36$ or distance $\approx 0.68$ ).
} 
average, an increase in diversity by one standard deviation (approximately 0.55) is associated with 6.31 additional citations, holding all other variables constant. In the robustness section we further examine this finding more closely, finding some conflicting evidence.

Insert Exhibit 8:

Robustness:

We examine several limitations in the above analysis here and attempt to strengthen our findings. First we look more closely at our second hypothesis and explore whether the increased impact of knowledge in the semi periphery is due to increased citations from within the school of thought or increased attention from outside the school of thought. Since we are predicting that distance has a curvilinear relationship with total citations ranging from the core to the periphery, we split our papers into two groups core to semi-periphery and semi-periphery to periphery based on the distance trend noted in Exhibit 9 by dividing the data above and below the optimal distance point of the quadratic.

For each of these two parts of the data we replaced the dependent variable in Model II with the number of citations for that paper originating from outside its cluster and from within its cluster, alternately, to see if increasing the distance from the center of 
a cluster led to changes in expected citations. ${ }^{6}$ We proceeded to test whether changes in distance led to changes in citations originating outside the cluster, which would support our theory that drawing from knowledge outside the cluster tends to lead to more impact on knowledge outside the cluster. This new model confirmed that distance did attract significantly more out of cluster citations from the core to the semi-periphery and fewer out of cluster citations from the semi-periphery to the periphery.

Utilizing the peaks to either side of the central plateau identified with our splines $(d=0.3$ and 0.7$)$, we then test whether changes in distance led to changes in the number of citations from the same cluster - as before we predicted a positive change from the core to the apex of the curve and a negative change from the midpoint to the periphery. This would bolster the idea that a paper is combining new knowledge from outside the cluster with knowledge from that cluster to generate valuable contributions within its cluster. We used citations received from within cluster (Same Cluster Citations) as our dependent variable and found significant support for our predictions.

Within the core to semi-periphery, an increase in distance of 0.01 is, on average, associated with an increase in citations of $4.7 \%$ and $4.8 \%$ for in cluster and out of cluster citations respectively, holding all other variables unchanged. For the semi-periphery to periphery we found that an increase in distance of 0.01 is associated, on average, with a decrease in same cluster citations by a factor of $-0.5 \%$ and outside cluster citations of 3.8\%, holding all other variables unchanged, as shown in Exhibit 9 (Long 1997). ${ }^{7}$

\footnotetext{
${ }^{6}$ For two of these four models there were too few papers with zero citations to justify a zero-inflated model.and the standard NB model produced a sufficiently accurate fit for this analysis. Thus for these two models we used a negative binomial regression (see Exhibit 9).

${ }^{7}$ In this case the percentage change in citations is equal to $\exp \left(\beta^{*} \delta\right)$ where $\delta$ is the incremental change in which you are interested and $\beta$ represents the respective coefficient in the model.
} 
Insert Exhibit 9:

Second we examined more closely our third hypothesis about the diversity of cluster experience. While we found an overall positive impact associated with diversity in our earlier analysis we suspect that different explanatory mechanisms may be at work depending on how high-impact the authors of the new knowledge are. We differentiate between high-impact authors, for whom diversity of publications may be reflective of high-impact new knowledge generation, and low impact authors, who may be motivated differently when publishing in many schools of thought without garnering citations. As an exploratory analysis, we therefore calculate an expected citation rate for each paper using the maximum of each papers' authors' average citations within our data and use this to partition our papers by 'expected citations rates' and test our hypothesis on these portions separately.

We re-ran Model III on those papers with expected citations above and below the median and in the top decile. We found similar results with respect to both direction and significance for diversity of publications among the papers with expected citations in the lower half. For those papers with expected citations in the upper half, however, we found that an author's increasing diversity of publications was associated with a small but significant decrease in citations. This result supports our competing Hypothesis IIIb. We additionally ran Model III including only the top $10 \%$ of papers based on expected 
citation rate. We were surprised to find that for this highest decile of papers neither hypothesis IIIa nor IIIb is supported. See Table 6 for a summary of results.

Insert Table 6:

Third we wish to confirm that our clustering algorithm is identifying meaningful schools of thought. While it compares favorably to other algorithms of its kind we wish to separately test whether the specific tests we claim remain if we randomize the cluster assignment for all papers in the same proportions that exist in our dataset and monitor our results for any changes. Our first hypothesis claims that being in a cluster is advantageous in garnering citations - once we randomize citation assignments (and therefore cluster membership) this effect should disappear if the clusters are in fact meaningful. This would add confidence that our results are not an artifact of clustering or statistical methodology. We find that indeed after randomizing we do lose significance for our binary cluster variable as expected. The cluster assignments were successfully randomized $\left(\chi_{(324)}^{2}=276.0230 p=0.975\right)$. The coefficients for our new binary cluster membership variable in our model are now insignificant (NB portion: $p=0.403$; Zero Inflation portion: $p=0.361$ ). These results support the validity of our clustering methodology

Lastly we want to further rule out the possibility that the excess zero counts in our data obscured the true trends, despite our use of the ZINBR formulation. To accomplish this we excluded all zero citation papers and proceeded to refit our data with a standard 
Negative Binomial model. The direction and significance of our coefficients in the NB portion of our previous models remain unchanged. We do not believe that the zeroinflation portion of our model was incorrectly identifying and modeling the excess zero counts or obscuring the trend among those papers which received citations.

In aggregate, the findings in this section give us added confidence in our findings

for our first two hypothesis and undermine some confidence in our findings for our third hypothesis. In addition we have also added robustness to the accuracy of our clustering methodology. In the section to follow we discuss the implications and consequences of our findings.

\section{Discussion}

We have argued that there exists strong incentives for researchers to position knowledge between and within schools of thought, but this does not necessarily imply that authors are fully aware of this reward structure. Nor does this imply that an author who was aware of this structure could purposely increase his/her impact by purposefully repositioning his/her citation structure or knowledge base.

Indeed in our discussions with leading researchers in the field of management we do find that authors are generally aware of and think about themselves in relation to schools of thought, though we also find that the individual representation of such schools, while on average close to our clusterings, does vary - particularly when addressing subtle 
positioning choices. ${ }^{8}$ We believe the mechanisms which explain our implicit incentive structures within and between schools of thought are largely driven by implicit and cognitive forces rather than conscious and purposeful ones - by shaping worldview schools of thought can powerfully affect the development of knowledge creation without explicit fiat or governance mechanisms.

The incentive structures on the individual micro-level cascade to have powerful and systematic effects on the development of their field over time. Understanding what knowledge contributions tend to get attention and have impact is crucial to understanding how that field dynamically evolves and develops.

Functionally, schools of thought provide "small world" advantages to the process of knowledge development. Schools provide the local dense connection networks that lend themselves to learning and reputation. At the same time, the incentives toward semi-periphery positioning encourages school boundary spanning. Our findings nicely reinforce the small world findings in the arena of knowledge creation and provide a new perspective and additional explanatory analysis on the social and intellectual underpinnings of this process in the knowledge creation context.

Our results agree with the broader research which argues that knowledge creation occurs through a moderated combination of exploration and exploitation. While we support the basic premises of positioning theory, we take into consideration key social dimensions of intellectual positioning previously ignored. We provide and analyze new boundaries for the analysis of exploration. We build on previous research which delineated schools of thought by looking at new knowledge creation from the author-

\footnotetext{
${ }^{8}$ Indeed since statistical correlation does not imply causation an explicit positioning and, in particular, a shallow manipulation of citation structure without a change in knowledge base and search structure is unlikely to affect impact deeply.
} 
level positioning perspective. In doing so we quantitatively test for the first time the actual benefits that membership and position with a school of thought at time of publication has on a creator of new knowledge.

More generally, the findings of this paper explore the consequences of social organization on cooperative knowledge creation. We believe that this sort of knowledge creation, where new knowledge developers share knowledge and coalesce into cohesive and distinct intellectual and social groups is crucial in new knowledge development. We create a quantitative framework for analyzing the individual by individual incentive structure that, in aggregate, shape how knowledge develops.

We speculate that the robust incentive structures we find in clusters are maintained through selection forces within the knowledge environment - insipient clusters which encourage too much exploration lose their integrity and fail to develop strong internal paradigms, while incipient clusters which are too internally focused may not attract sufficient attention or become too stagnant to gain momentum. Clusters that balance these two extremes in the way we describe seem to have survived to populate our dataset.

\section{Conclusions}

By applying performance measures to positioning in and around schools of thought we reveal that where knowledge is positioned has a significant impact on its performance. Indeed, by studying a complete set of articles in the top 41 journals in the social science field of micro and macro management, we found new knowledge which is 
positioned within a school of thought can expect to get, on average, 15.03 more citations. Within a school of thought, knowledge positioned in the semi-periphery of a school of thought (representing knowledge which builds on a mix of knowledge common and unusual in that school) of thought rather than at its center or periphery results in 2.88 additional citations (+/- 1 S.D.).

We emphasize the complexity of new knowledge positioning because we see the act of new knowledge development to be a deeply socially-structured process. Schools of thought represent more than a post hoc artifact of ideas but a dynamic and important force in the future creation and knowledge landscape. This is in keeping with the findings of researchers who show that firms which both explore and exploit in specific ways over time tend to outperform firms that do not (Rosenkopf and Nerkar 2001; Nerkar 2003; Gittelman 2003 draft).

Our goal in this paper was to better understand the consequences of implicit and explicit positioning of researchers between and among schools of thought. Such positioning problems are by their nature complex and multi-dimensional. We develop a strategic framework for analyzing how new knowledge is positioned within the knowledge landscape considering seriously the social structure of that landscape specifically the powerful effects of schools of thought. We find that new knowledge was positioned by its creators under the stress of two search tensions - being a part of an identifiable school of thought and simultaneously reaching beyond that school to draw on outside knowledge.

There are powerful advantages and subtle disadvantages provided by homophilous social groups, or schools of thought, in the process of knowledge creation. 
While such schools of thought, which represent mini-paradigms or work views, provide an audience and an intellectual structure to build on, we find that authors must also, in moderation, resist their pull and reach out beyond them to introduce fresh ideas and to appeal to outside audiences. This tension between gaining the advantages of joining a school of thought at the same time resisting homogenization from that school of thought is a significant challenge for new knowledge developers while searching for new ideas, and an important part of the dynamic evolution and development of new knowledge. 


\section{References:}

Abrahamson, E. (1996). "Management fashion." Academy of Management Review 21(1): 254-285.

Amir, S. (1985). "On the Degree of Interdisciplinarity of Research Programs - a Quantitative Assessment." Scientometrics 8(1-2): 117-136.

Barnett, W. P. and O. Sorenson (2002). "The Red Queen in organizational creation and development." Industrial and Corporate Change 11(2): 289-325.

Barney, J. (1986). Types of competition and the theory of strategy: Towards an integrative framework. Academy of Management Review. 11: 791-800.

Bayer, A. E. and J. Folger (1966). "Some Correlates of a Citation Measure of Productivity in Science." Sociology of Education 39(4): 381-390.

Birnbaum, P. H. (1981). "Academic Interdisciplinary Research - Characteristics of Successful Projects." Sra-Journal of the Society of Research Administrators 13(1): 5-16.

Birnbaum, P. H. (1981). "Integration and Specialization in Academic Research." Academy of Management Journal 24(3): 487-503.

Blackburn, R. S. (1990). "Organizational-Behavior - Whom Do We Talk to and Who Talks to Us." Journal of Management 16(2): 279-305.

Brown, J., Duguid, P (1991). "Organizational Learning and Communites of Practice." Organization Science 2(1): 40-57.

Brown, J., Duguid, P (2000). "Knowledge and Organization." Organization Science 12(2): 198-213.

Burt, R. (unpublished). "Social Capital: Principles and Applications."

Castro, P. L., Maria Luísa (2001). "Old and new ideas about the environment and science: An exploratory study." Environment \& Behavior 33(3): 400-423.

Choi, S. C. C., A.T. (2004). "Private Label Positioning: Vertical vs. Horizontal Differentiation from the National Brand." Unpublished.

Coe, R. and I. Weinstock (1984). "Evaluating the Management Journals - a 2nd Look." Academy of Management Journal 27(3): 660-666.

Coe, R. W., I. (1969). "Evaluating journal publications: Perceptions versus reality." AASCB Bulletin(1): 23-37.

Cole, S. and J. R. Cole (1967). "Scientific Output and Recognition - Study in Operation of Reward System in Science." American Sociological Review 32(3): 377-390.

Crane, D. (1972). Invisible Colleges Diffusion of Knowledge in Scientific Communities. Chicago, IL, University of Chicago Press.

Crane, D. (1980). "An Exploratory-Study of Kuhnian Paradigms in Theoretical HighEnergy Physics." Social Studies of Science 10(1): 23-54.

Crane, D. (1989). "How Scientists Communicate - a Citation Classic Commentary on Invisible-Colleges - Diffusion of Knowledge in Scientific Communities by Crane,D." Current Contents/Arts \& Humanities(22): 14-14.

Culnan, M. J. (1986). "The Intellectual-Development of Management-InformationSystems, 1972-1982 - a Cocitation Analysis." Management Science 32(2): 156172. 
Culnan, M. J. (1987). "Mapping the Intellectual Structure of Mis, 1980-1985 - a Cocitation Analysis." Mis Quarterly 11(3): 341-353.

Culnan, M. J., C. A. Oreilly, et al. (1990). "Intellectual Structure of Research in Organizational-Behavior, 1972-1984 - a Cocitation Analysis." Journal of the American Society for Information Science 41(6): 453-458.

Domingos, P. (2003). Prospects and Challenges for Multi-Relational Data Mining. SIGKDD Explorations.

Domingos, P. H., G (2001). "A General Method for Scaling Up Machine Learning Algorithms." Unpublished.

Doreian, P. (1988). "Testing Structural-Equivalence Hypotheses in a Network of Geographical Journals." Journal of the American Society for Information Science 39(2): 79-85.

Downs, A. (1957). "An Economic Theory of Political Action in a Democracy." Journal of Political Economy 65(2): 135-150.

Ennis, J. G. (1992). "The Social-Organization of Sociological Knowledge - Modeling the Intersection of Specialties." American Sociological Review 57(2): 259-265.

Extejt, M. M. and J. E. Smith (1990). "The Behavioral-Sciences and Management - an Evaluation of Relevant Journals." Journal of Management 16(3): 539-551.

Fleming, L. (2001). "Recombinant uncertainty in technological search." Management Science 47(1): 117-132.

Fleming, L. and O. Sorenson (2001). "Technology as a complex adaptive system: evidence from patent data." Research Policy 30(7): 1019-1039.

Garfield, E. (1983). "How to Use Citation Analysis for Faculty Evaluations, and When Is It Relevant .2." Current Contents(45): 5-14.

Gasper, J. T. (2005). Political News. Annual Meeting of the Public Choice Society.

Gittelman, M. (2003 draft). "Does geography matter for science based firms? Epistemic communities and the geography of research and patenting in biotechnology."

Gmur, M. (2003). "Co-citation analysis and the search for invisible colleges: A methodological evaluation." Scientometrics 57(1): 27-57.

Gomezmejia, L. R. and D. B. Balkin (1992). "Determinants of Faculty Pay - an Agency Theory Perspective." Academy of Management Journal 35(5): 921-955.

Guha, S. M., A; Mishra, N; Motwana, R; O'Callaghan (2003). "Custering Data Streams: Theory and Practice." Unpublished.

Hargens, L. L. (2000). Graphing micro-regions in the web of knowledge: A comparative reference network analysis. Web of Knowledge - a Festschrift in Honor of Eugene Garfield: 497-516.

Hotelling, H. (1929). "Stability in Competition." The Economic Journal(39): 41-57.

Johnson, J. L. and P. M. Podsakoff (1994). "Journal Influence in the Field of Management - an Analysis Using Salancik Index in a Dependency Network." Academy of Management Journal 37(5): 1392-1407.

Kandylas, B. (2005). "A Mixture Model for Document Clustering by Citations." Unpublished.

Kandylas, V. U., L; Forster, D (2005). "Winner-Take-All EM Clustering." Unpublished.

Katila, R. and G. Ahuja (2002). "Something old, something new: a longitudinal study of search behavior and new product introduction." Academy of Management Journal 45(6): 1183-1194. 
Kripke, S. (1984). Wittgenstein on Rules and Private Language. Cambridge, MA, Harvard University Press.

Krishna, R. V. (2001). "Voter Clustering and the Theory of Spacial Voting with Entry." Unpublished Draft.

Kuhn, T. S. (1970). The structure of scientific revolutions. International encyclopedia of unified science. Foundations of the unity of science, v. 2, no. 2. Chicago,, University of Chicago Press: xii, 210.

Lenk, P. (1983). "Mappings of Fields Based on Nominations." Journal of the American Society for Information Science 34(2): 115-122.

Levinthal, D. (1991). Organizational adaptation and environmental selection Interrelated processes of change. Organization Science. 2: 140-145.

Levinthal, D. A. (1997). Adaptation on rugged landscapes. Management Science. 43: 934-950.

Levinthal, D. A. (1998). The Slow Pace of Rapid Technological Change: Gradualism and Punctuation in Technological Change. Industrial \& Corporate Change. 7: 217247.

Levinthal, D. A. and M. Warglien (1999). Landscape Design: Designing for Local Action in Complex Worlds. Organization Science. 10: 342-357.

Lodahl, J. B. G., G. (1972). "The Structure of Scientific Fields and the Functioning of University Graduate Departments." American Sociological Review 37: 57-72.

Long, J. S. (1997). Regresson Models for Catagorical and Limited Dependent Variables. Thousand Oaks, CA, Sage Publications.

March, J. G. (1991). Exploration and exploitation in organizational learning. Organization Science. 2: 71-87.

March, J. G. and Z. Shapira (1987). Managerial Perspectives on Risk and Risk Taking. Management Science. 33: 1404-1418.

March, J. G. and H. A. Simon (1958). Organizations. New York,, Wiley: 262.

March, J. G. and R. I. Sutton (1997). Organizational performance as a dependent variable. Organization Science. 8: 698-706.

Marks, U. G. A., S. (2001). "Experiments in Competative Product Positioning: Actual Behavior Compared to Nash Solutions." Schmalenbach Business Review 53: 150174.

McCain, K. W. (1986). "Cross-Disciplinary Citation Patterns in the History of Technology." Proceedings of the American Society for Information Science 23: 194-198.

McCain, K. W. (1987). "Citation Patterns in the History of Technology." Library \& Information Science Research 9(1): 41-59.

McGann, A. J. (2002). "the Advantages of Ideological Cohesion." Journal of Theoretical Politics 14(1): 37-70.

Merton, R. K. (1965). On the Shoulders of Giants: A Shandean Postscript. New York, The Free Press.

Merton, R. K. (1972). The sociology of science. Chicago, IL, University of Chicago Press.

Meyer, M., Zucker, LG (1989). Permanently Failing Organizations. Newbury Park, CA, Sage Publications. 
Meyer, M. W. (1994). Measuring Performance in Economic Organizations. The Handbook of economic sociology. R. Swedberg. Princeton, Princeton University Press ;Russell Sage Foundation: viii, 835.

Meyer, M. W. (1999). "Notes from a border discipline: Has the border become the center?" Contemporary Sociology - A Journal of Reviews 28(5): 507-510.

Mintzberg, H. (1978). Patterns in strategy formulation. Management Science. 24: 934948.

Moody, J. (2001). "Peer influence groups: identifying dense clusters in large networks." Social Networks 23(4): 261-283.

Morris, S., C. DeYong, et al. (2002). DIVA: a visualization system for exploring document databases for technology forecasting. Computers \& Industrial Engineering. 43: 841-862.

Nelson, R. R. and S. G. Winter (1982). An evolutionary theory of economic change. Cambridge, Mass., Belknap Press of Harvard University Press: xi, 437.

Nerkar, A. (2003). "Old is gold? The value of temporal exploration in the creation of new knowledge." Management Science 49(2): 211-229.

Osareh, F. (1996). "Bibliometrics, citation analysis and co-citation analysis: A review of literature .2." Libri 46(4): 217-225.

Pantel, P. L., D (2002). Discovering Word Senses from Text. SIGKDD, Edmonton, Alberta, Canada.

Pantel, P. L., D (2002). Document Clustering with Committees. SIGIR, Tampere, Finalnd.

Pfeffer, J. (1993). "Barriers to the Advance of Organizational Science - Paradigm Development as a Dependent Variable." Academy of Management Review 18(4): 599-620.

Podsakoff, P. M. M., S. B.; Bachrach, D.G.; Podsakoff, N.P. (2005). "The Influence of Management Jornals in the 1980s and 1990s." Strategic Management Journal 26: 473-488.

Popescul, A. F., G.W.; Lawrence, S; Ungar, L.H.; Giles, L.C. (2000). Clustering and Identifying Temporal Trends in Document Databases. IEEE Advances in Digital Libraries, Washington, DC.

Powell, W. W., K. W. Koput, et al. (1996). Interorganizational collaboration and the locus of innovation: Networks of learning in biotechnology. Administrative Science Quarterly. 41: 116-145.

Ramos-Rodriguez, A. R. and J. Ruiz-Navarro (2004). "Changes in the intellectual structure of strategic management research: A bibliometric study of the Strategic Management Journal, 1980-2000." Strategic Management Journal 25(10): 9811004.

Rosenkopf, L. and A. Nerkar (2001). "Beyond local search: Boundary-spanning, exploration, and impact in the optical disk industry." Strategic Management Journal 22(4): 287-306.

Salancik, G. R. (1986). "An Index of Subgroup Influence in Dependency Networks." Administrative Science Quarterly 31(2): 194-211.

Sharplin, A. D. and R. H. Mabry (1985). "The Relative Importance of Journals Used in Management Research - an Alternative Ranking." Human Relations 38(2): 139149. 
Siggelkow, N. (2001 draft). "Who reads my papers anyways? a survey of journal readership and reputation."

Small, H. (1999). "A passage through science: Crossing disciplinary boundaries." Library Trends 48(1): 72-108.

Small, H. (2003). "Paradigms, citations, and maps of science: A personal history." Journal of the American Society for Information Science and Technology 54(5): 394-399.

Small, H. G. (1976). "Structural Dynamics of Scientific Literature." International Classification 3(2): 67-74.

Small, H. G. (1978). "Cited Documents as Concept Symbols." Social Studies of Science 8(3): $327-340$.

Small, H. G. and D. Crane (1979). "Specialties and Disciplines in Science and SocialScience - Examination of Their Structure Using Citation Indexes." Scientometrics 1(5-6): 445-461.

Stigler, G. J., S. M. Stigler, et al. (1995). "The Journals of Economics." Journal of Political Economy 103(2): 331-359.

Trajtenberg, M. (1990). A Penny for Your Quotes: Patent Citations and the Value of Innovations. RAND Journal of Economics. 21: 172-187.

Usdiken, B. and Y. Pasadeos (1995). "Organizational Analysis in North-America and Europe - a Comparison of Cocitation Networks." Organization Studies 16(3): 503-526.

Uzzi, B. S., J. \& Delis, D. (forthcoming). "Emergence: The Origin and Evolution of Career Networks in the Broadway Musical Industry, 1877-1995."

Watts, D. J. (1999). "Networks, dynamics, and the small-world phenomenon." American Journal of Sociology 105(2): 493-527.

Wenger, E. (1998). Communities of Practice: Learning, Meaning and Identity. Cambridge, United Kingdom, Cambridge University Press.

Williamson, O. E. (1975). Markets and hierarchies, analysis and antitrust implications, a study in the economics of internal organization. New York,, Free Press: xvii, 286.

Williamson, O. E. (1979). Transaction-Cost Economics: The Governance of Contractual Relations. Journal of Law \& Economics. 22: 233-61. 


\section{Appendix A:}

Description of Clustering Methodology:

Our clustering algorithm clusters items in three steps (repeated when doing iterated "overlapping" clustering). In Step I, we make a single pass over the data and construct several rough clusters. In Step II, we get a collection of high quality clusters, called committees, based on the clusters we get in Step I. These committees are tight and differ from each other, indicating high inter-group similarity and low intra-group similarity between papers. In Step III, each element is either assigned to its most similar clusters, or added to the residue list if it is not similar enough to any cluster. We now give a more detailed description of each step.

Step I:

The objective of this step is to find a collection of rough clusters over the data, from which we can form high-quality committees in step II. For each element, we compute its similarity to the centroid of every cluster in our cluster list, which is initially empty. The centroid is the average citation structure of all papers in the cluster. We say an element is far away from all other clusters if its similarity to every existing cluster is below some similarity threshold $\theta_{1}$. The algorithm then adds this element as a new singleton cluster to the cluster list. Otherwise, the element is assigned to its most similar cluster.

Step II:

The second step of the clustering algorithm finds a set of committees, which are tight and well-scattered in the similarity space. The output of Step I consists of rough and low- 
quality clusters - clusters which might be very close to each other, and have a very small number of elements, even singletons. We call these 'committee candidates'. Based on those candidates, the algorithm finds as many committees as possible on the condition that each newly discovered committee is big enough and not too similar to any existing committee.

This selection process uses the parameters "minsize" and $\theta_{2}$. The parameter "minsize" in line 9 and line 12 below filters out small-size clusters, and reflects our preference for bigger committees. For each candidate, it is only kept as a committee if it is big enough, and more important, its similarity to every committee candidate is below some threshold $\theta_{2}$ for cluster cohesiveness. Cluster cohesiveness is calculated by averaging the similarity between each of its elements and its centroid,

$$
\frac{\sum_{i=1}^{n_{C}} \operatorname{sim}\left(e_{i}, c e n_{C}\right)}{n_{C}}
$$

where $C$ represents a cluster; $i$ indexes papers in cluster $C$; and $\operatorname{sim}(\cdot)$ is the measure of similarity as previously defined, and $n_{C}$ is the number of papers in cluster C. Each committee that is found in this step will define one of the final output clusters of this algorithm.

\section{Step III:}

The final step of the algorithm resembles the traditional clustering methodologies Kmeans and $\mathrm{CBC}$ in that each element is assigned to its most similar clusters. In this case, for each element, if its similarity to a committee exceeds some high similarity threshold $\theta_{3}$, it is assigned to the cluster containing the committee. If an element's similarity to every cluster is below $\theta_{3}$, i.e. it is far away from any cluster, it is added to the list of residues. 


\section{Pseudocode}

Input: A list of elements $\mathrm{E}$ to be clustered, thresholds $\theta_{1}, \theta_{2}$, and $\theta_{3}$, and minimum size minsize.

\section{Step 1:}

$1 \quad C \leftarrow\{\} ;$ Cen $\leftarrow\{\}$

2 for each $e \in E$

3 if $\operatorname{sim}(e, c)<\theta_{1}$, for $\forall c \in C$, then

$4 \quad C \leftarrow C \cup\{\{e\}\}$

$5 \quad$ else $c^{\prime}=\arg \max [\operatorname{sim}(e, c)]$

6

7

8

9

\section{Step 2:}

1 new_C $C\{\}$

2 for each $c \in C$

3 cen_v $\leftarrow$ centroid vector of $\mathrm{c}$

$4 \quad$ num $\leftarrow$ number of elements in $\mathrm{c}$

$5 \quad \operatorname{cohesiveSim}(c)=\sum_{e \in c} \operatorname{sim}\left(e, c e n_{-} v\right) /$ num

6 end for

7 for each $c \in C$

8 if $\operatorname{sim}(c, x)<\theta_{2}$, for $\forall x \in C$, then

9 if $\operatorname{size}(\mathrm{c})>$ minsize,

$10 \quad$ new_ $C \leftarrow$ new_ $C \bigcup\{c\}$

11 end if

12 else $s \leftarrow\left\{x: x \in C, \operatorname{sim}(c, x)<\theta_{2} \wedge \operatorname{size}(x)>\min \operatorname{size}\right\}$

$13 \quad c^{\prime}=\underset{x \in s}{\arg \max }[\operatorname{cohesiveSim}(x)]$

$$
\begin{aligned}
& n e w_{-} C \leftarrow n e w_{-} C \bigcup\left\{c^{\prime}\right\} \\
& \text { end if }
\end{aligned}
$$

Step 3:

$1 \quad L \leftarrow n e w_{-} C ; R \leftarrow\{\}$

2 for each $e \in E$

3 for each $c \in$ new_C

$4 \quad$ if $\operatorname{sim}(e, c)>\theta_{3}$, then

$5 \quad l \leftarrow l \bigcap\{e\}, l \in L \wedge c \subseteq l$

6 end if

7 end for

8 if $e \notin l$, for $\forall l \in L$, then 


$$
R \leftarrow R \bigcup\{e\}
$$

10 end if

11 end for

Output: A list of clusters 


\section{Exhibits, Table, Figures:}

Table 1: Fields in which papers in our study fall (as specified by ISI classification of journal) ${ }^{9}$

$\begin{array}{cccl}\text { Citations } & \text { Papers } & \text { Average Cites/Paper } & \text { Field } \\ 921,507 & 40,392 & 22.81 & \text { Psychology } \\ 357,996 & 42,193 & 8.48 & \text { Management } \\ 350,254 & 5,737 & 61.05 & \text { Behavior } \\ 181,531 & 27,063 & 6.71 & \text { Sociology \& Anthropology } \\ 51,692 & 9,081 & 5.69 & \text { No Category } \\ 38,089 & 12,176 & 3.13 & \text { Economics } \\ 14,284 & 2,059 & 6.94 & \text { Political Science \& Public Administration }\end{array}$

Table 2: Journals and Summary Statistics

$\begin{array}{cccl}\text { Citations } & \text { Papers } & \text { Average Cites/Paper } & \text { Journals } \\ 297,182 & 7,775 & 38.22 & \text { Journal of Personality and Social Psychology } \\ 195,697 & 3,530 & 55.44 & \text { Psychological Bulletin } \\ 154,557 & 2,207 & 70.03 & \text { Psychological Review } \\ 131085 & 14509 & 9.03 & \text { American Journal of Psychology } \\ 93,836 & 8,039 & 11.67 & \text { American Sociology Review } \\ 91,083 & 4,636 & 19.65 & \text { Journal of Applied Psychology } \\ 64,297 & 4,470 & 14.38 & \text { Management Science } \\ 60,031 & 10,948 & 5.48 & \text { American Journal of Sociology } \\ 55,953 & 2,991 & 18.71 & \text { Administrative Science Quarterly } \\ 49,606 & 2,360 & 21.02 & \text { Academy of Management Journal } \\ 32,756 & 1,501 & 21.82 & \text { Academy of Management Review } \\ 31,554 & 1,283 & 24.59 & \text { Strategic Management Journal } \\ 27,664 & 8,076 & 3.43 & \text { Social Forces } \\ 23,448 & 877 & 26.74 & \text { Organizational Behavior and Human Performance } \\ 23,374 & 9,393 & 2.49 & \text { Harvard Business Review } \\ 22,498 & 1,717 & 13.1 & \text { Journal of Vocational Behavior } \\ 22,384 & 5,150 & 4.35 & \text { Perspectives in Psychology } \\ 20,594 & 2,502 & 8.23 & \text { Human Relations } \\ 17,836 & 1,116 & 15.98 & \text { Organizational Behavior and Human Decisions } \\ 14,596 & 5,132 & 2.84 & \text { Industrial Labor Relations Review } \\ 14,256 & 1,566 & 9.1 & \text { Journal Human Resources } \\ 12,022 & 1,321 & 9.1 & \text { Journal of Conflict Resolution } \\ 11,658 & 875 & 13.32 & \text { Journal of Management } \\ 9,082 & 1,185 & 7.66 & \text { Journal of International Business Studies } \\ 8,144 & 2,257 & 3.61 & \text { Journal of Management Studies } \\ 8,028 & 1,822 & 4.41 & \text { California Management Review } \\ & & & \end{array}$

\footnotetext{
${ }^{9}$ All citation counts as of 2003 .
} 


$\begin{array}{cccl}8,012 & 930 & 8.62 & \text { Journal of Occupational Psychology } \\ 7,846 & 904 & 8.68 & \text { Decision Sciences } \\ 7,221 & 1,868 & 3.87 & \text { Sloan Management Review } \\ 7,050 & 1,534 & 4.6 & \text { Industrial Relations } \\ 7,021 & 868 & 8.09 & \text { Journal of Organizational Behavior } \\ 5,633 & 1,598 & 3.53 & \text { Journal of Business Research } \\ 5,398 & 7,600 & 0.71 & \text { Monthly Labor Review } \\ 5,259 & 1,155 & 4.55 & \text { Journal of Applied Behavior Science } \\ 5,015 & 140 & 35.82 & \text { Research in Organizational Behavior } \\ 4,755 & 3,491 & 1.36 & \text { Long Range Planning } \\ 3,669 & 789 & 4.65 & \text { Organizational Dynamics } \\ 2,262 & 738 & 3.07 & \text { Administration Society } \\ 1,390 & 2,304 & 0.6 & \text { Labor Law Journal } \\ 757 & 693 & 1.09 & \text { Journal of Collective Negotiations in the Public Sector } \\ 590 & 1,114 & 0.53 & \text { Arbitration Journal }\end{array}$

Exhibit la and 1b: Average Bibliography Size by Year (left) and Average Total Citations Received by Year (right)

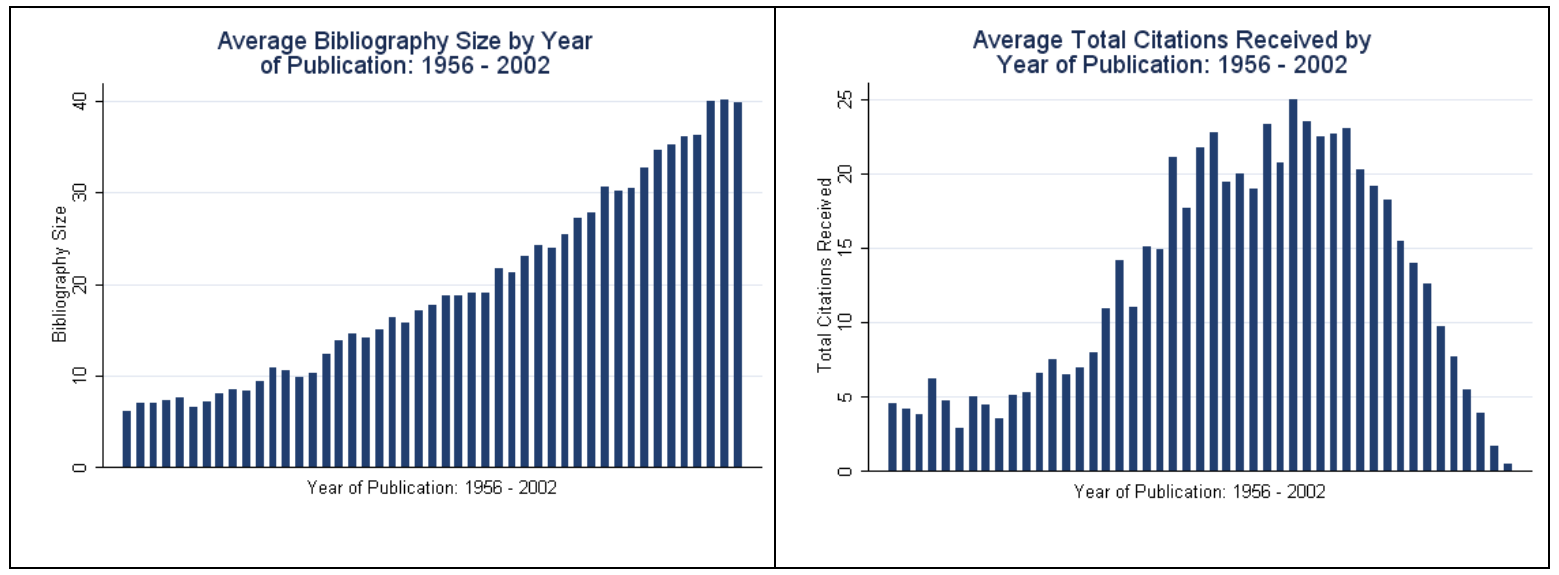

Exhibit 2: Papers per Year (top) and Journals Published or Covered by Data-source in that Year (bottom) 


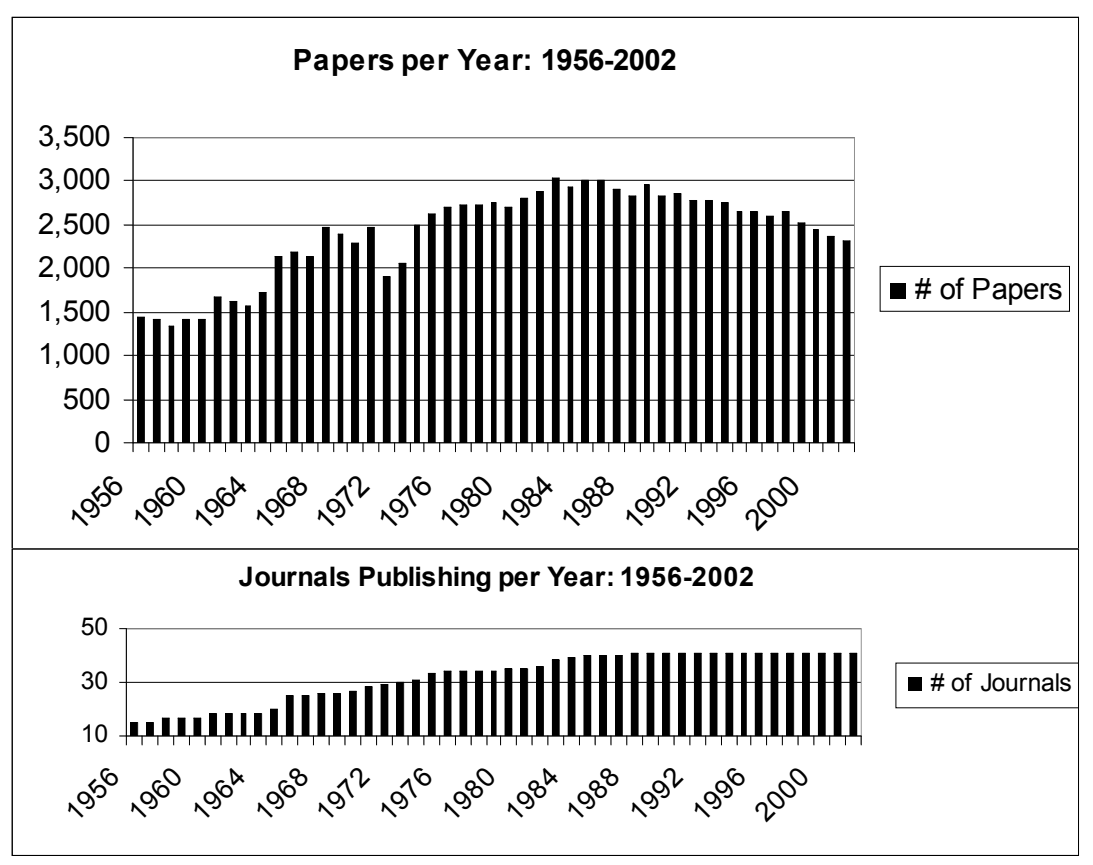

\section{Exhibit 3: Distance Between a Paper and it's Centroid}

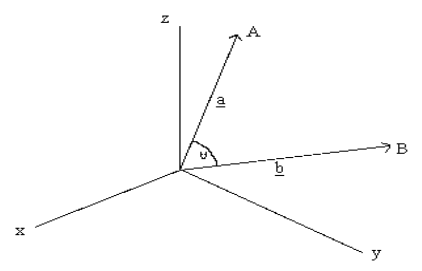

Table 3: Correlation Table and Descriptive Statistics

Descriptive Statistics $(n=113,014)$

\begin{tabular}{|l|l|c|c|c|c|c|c|c|}
\multicolumn{2}{|c|}{} & $\mathbf{1}$ & $\mathbf{2}$ & $\mathbf{3}$ & $\mathbf{4}$ & $\mathbf{5}$ & $\mathbf{6}$ & $\mathbf{7}$ \\
\cline { 2 - 10 } $\mathbf{1}$ & Total Citations & -- & & & & & & \\
$\mathbf{2}$ & Bibliography Size & $0.3013^{*}$ & -- & & & & & \\
$\mathbf{3}$ & CoAuthorship (binary) & $0.1443^{*}$ & $0.3228^{*}$ & -- & & & & \\
$\mathbf{4}$ & Cluster (binary) & $0.1460^{*}$ & $0.3930^{*}$ & $0.3590^{*}$ & -- & & & \\
$\mathbf{5}$ & Distance & $0.1803^{*}$ & $0.4070^{*}$ & $0.3634^{*}$ & $0.7347^{*}$ & -- & & \\
$\mathbf{6}$ & Distance Squared & $0.1308^{*}$ & $0.2889^{*}$ & $0.2655^{*}$ & $0.5433^{*}$ & $0.9137^{*}$ & -- & \\
7 & Diversity & $0.1232^{*}$ & $0.1773^{*}$ & $0.3455^{*}$ & $0.3079^{*}$ & $0.3217^{*}$ & $0.2403^{*}$ & -- \\
\hline
\end{tabular}

\begin{tabular}{|l|c|c|c|c|c|c|c|}
\hline Mean & 13.619 & 20.855 & 0.340 & 0.436 & 0.161 & 0.052 & 0.751 \\
\hline S.D. & 52.292 & 31.077 & 0.474 & 0.496 & 0.161 & 0.093 & 0.550 \\
\hline Min & 0 & 0 & 0 & 0 & 0.001 & 0 & 0 \\
\hline Max & 4580 & 801 & 1 & 1 & 1.480 & 2.190 & 2.453 \\
\hline
\end{tabular}




\section{Exhibit 4: Total Citations}

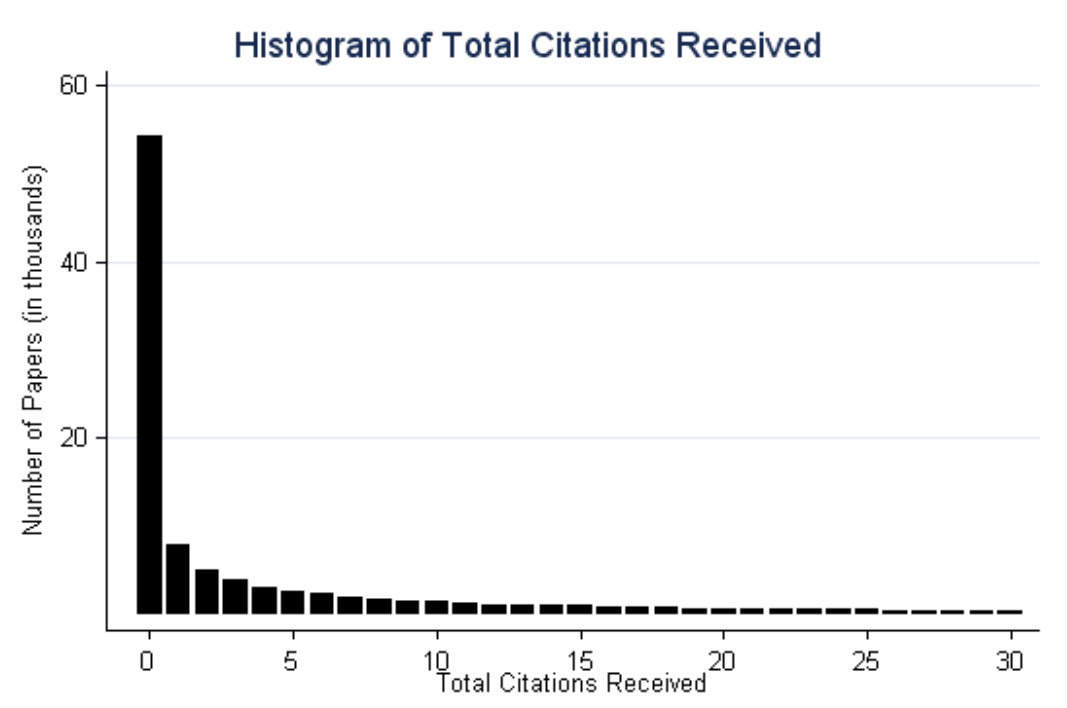

Distributions of papers by number of citations shows the extreme dispersion of the data on the right implying a negative binomial model and the large number of zero points on the left suggests that we ought to use a zero-inflated model. We cut the histogram off at 30 to make the trend visible. The papers excluded have total citations ranging up to 4,580 .

\section{Exhibit 5: Total Citations vs. Base Model Predicted Citations}

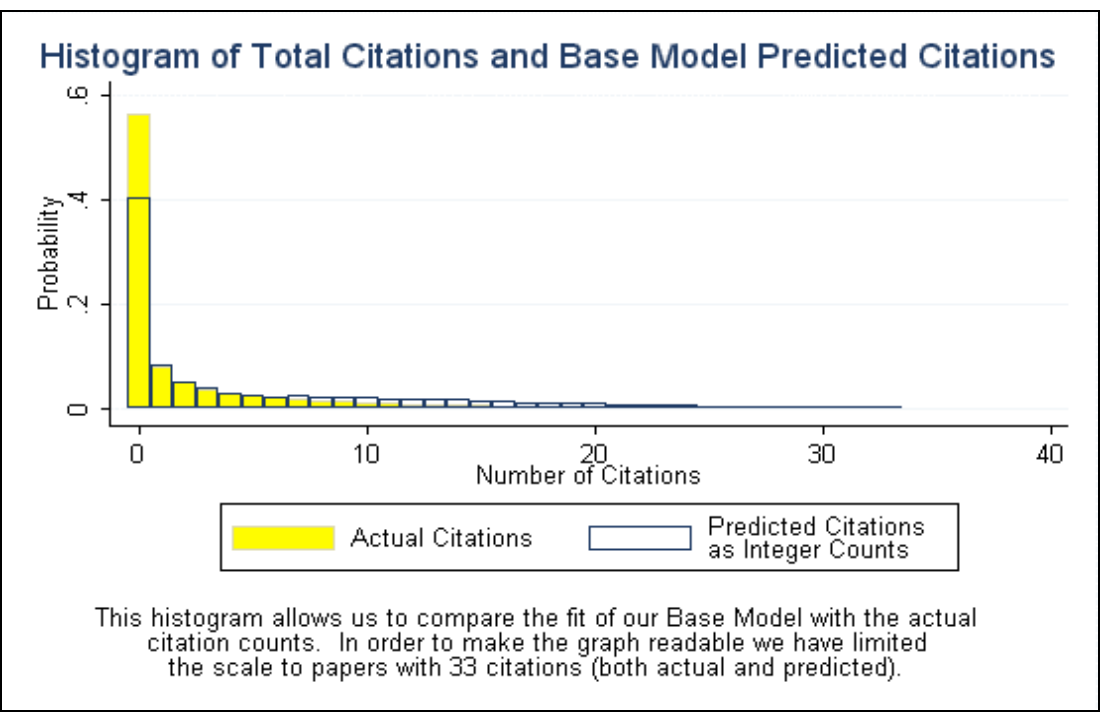


Illustrates how well Model I predicts the actual citations. On average there is good agreement between the densities indicating that Model I predicts an aggregate distribution of citations very similar to the true distribution of citations. 
Table 4: Table of Coefficients

\section{Coefficients and Significance Values for Zero Inflated Negative Binomial Models}

\begin{tabular}{|c|c|c|c|c|}
\hline & \multicolumn{4}{|c|}{ Negative Binomial Model Coefficients } \\
\hline & Base & 1 & 2 & 3 \\
\hline Cluster (binary) & & $0.253^{* * *}$ & & $0.192^{* * *}$ \\
\hline Distance & & \multicolumn{3}{|c|}{$2.743^{* * *}$} \\
\hline Distance Squared & & \multicolumn{3}{|c|}{$-2.439 * * *$} \\
\hline Diversity of Sources & & \multicolumn{3}{|r|}{$0.181^{* *}$} \\
\hline Year of Publication & sig. ${ }^{* * *}$ & sig. ${ }^{* * *}$ & sig. $^{* * *}$ & sig. ${ }^{* * *}$ \\
\hline Journal Dummies & sig. ${ }^{* * *}$ & sig. ${ }^{* * *}$ & sig. ${ }^{* * *}$ & sig. ${ }^{* * *}$ \\
\hline Bibliography Size & $0.013^{* * *}$ & $0.013^{* * *}$ & $0.010 * *$ & $0.012^{* * *}$ \\
\hline CoAuthorship (Binary) & $0.193^{* * *}$ & $0.194^{* * *}$ & $0.116^{* * *}$ & $0.035^{* * *}$ \\
\hline Cluster Sum & \multicolumn{4}{|r|}{$0.009 * * *$} \\
\hline Constant & \multicolumn{4}{|r|}{1.515} \\
\hline Alpha & \multicolumn{4}{|r|}{1.388} \\
\hline Log-likelihood & $-255,172$ & $-254,775$ & $-169,004$ & $-253,487$ \\
\hline \multirow[t]{3}{*}{ Number Observations } & 113,014 & 113,014 & 60,840 & 113,014 \\
\hline & \multicolumn{4}{|c|}{ Zero Inflated Model Coefficients (likelihood of zero count) } \\
\hline & Base & 1 & 2 & 3 \\
\hline Cluster (binary) & & $-0.756^{* * *}$ & & $-0.723^{* * *}$ \\
\hline Distance & & & -0.541 & \\
\hline Distance Squared & & & -0.415 & \\
\hline Diversity of Sources & & & & $-0.644^{* * *}$ \\
\hline Year of Publication & sig. ${ }^{* * *}$ & sig. ${ }^{* * *}$ & sig. ${ }^{* *}$ & sig. ${ }^{* * *}$ \\
\hline Journal Dummies & sig. ${ }^{* * *}$ & sig. ${ }^{* *}$ & sig. ${ }^{* *}$ & sig. ${ }^{* * *}$ \\
\hline Bibliography Size & $-0.590 * * *$ & $-0.538 * * *$ & $-0.335^{* * *}$ & $-0.504^{* * *}$ \\
\hline CoAuthorship (Binary) & $-1.650 * * *$ & $-1.621 * * *$ & $-1.416^{* * *}$ & $-1.688 * * *$ \\
\hline Cluster Sum & & & & $0.020 * * *$ \\
\hline Constant & 3.266 & 3.314 & 2.369 & 3.281 \\
\hline Number Zero Observations & 54,250 & 54,250 & 14,033 & 54,250 \\
\hline
\end{tabular}


Exhibit 6: Model I Predicted Citations vs. Cluster Membership

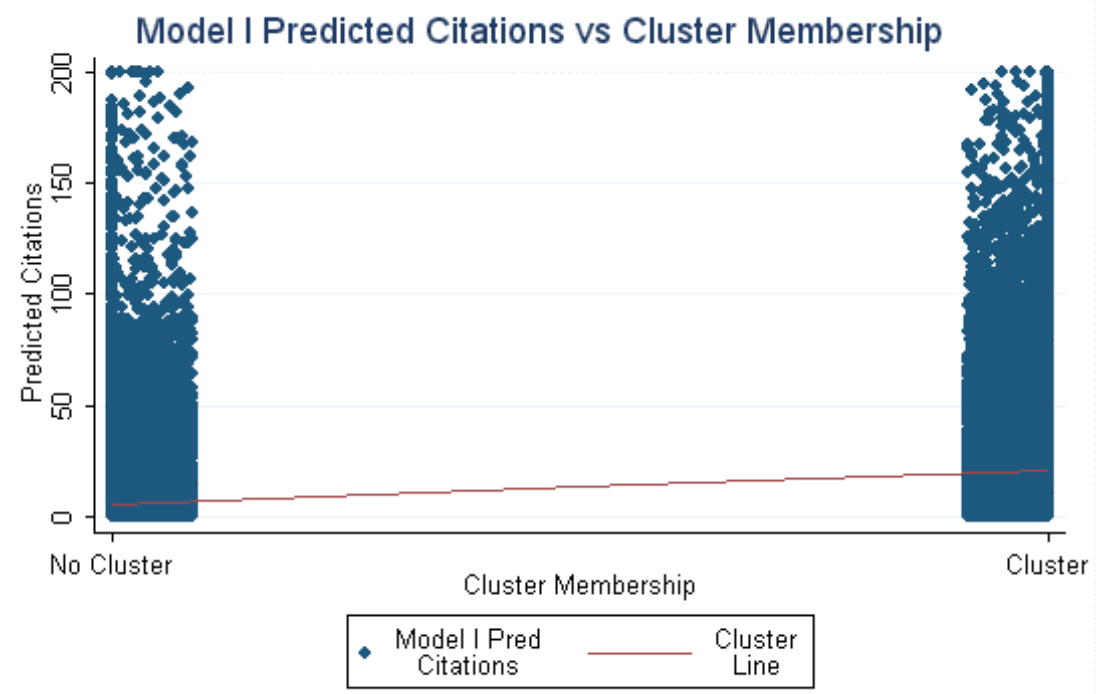

Table 5: Cluster Membership vs. Citations

\begin{tabular}{|c|c|c|c|}
\hline \multicolumn{3}{|c|}{ Cluster Membership vs Zero Citations } \\
\cline { 2 - 3 } & Cluster Membership? & \\
\hline Total Cites & No & Yes & Totals \\
\hline zero citations & 44,618 & 9,631 & 54,249 \\
\hline >=1 citations & 19,098 & 39,667 & 58,765 \\
\hline Totals & 63,716 & 49,298 & 113,014 \\
\hline
\end{tabular}

Exhibit 7: Top graph for full data, bottom for two sample clusters 3 and 16. 

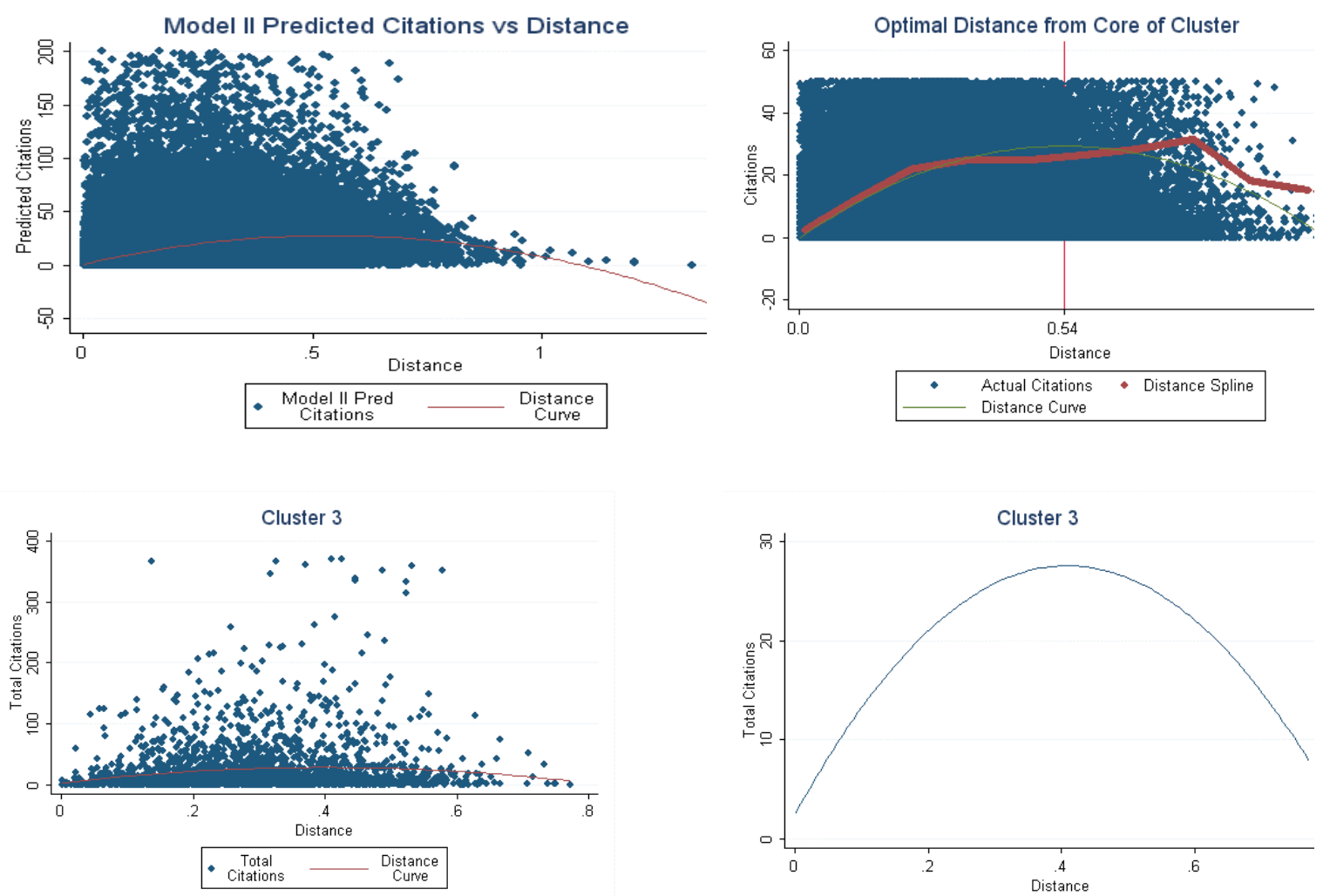

Exhibit 8: Model III Predicted Citations vs. Diversity

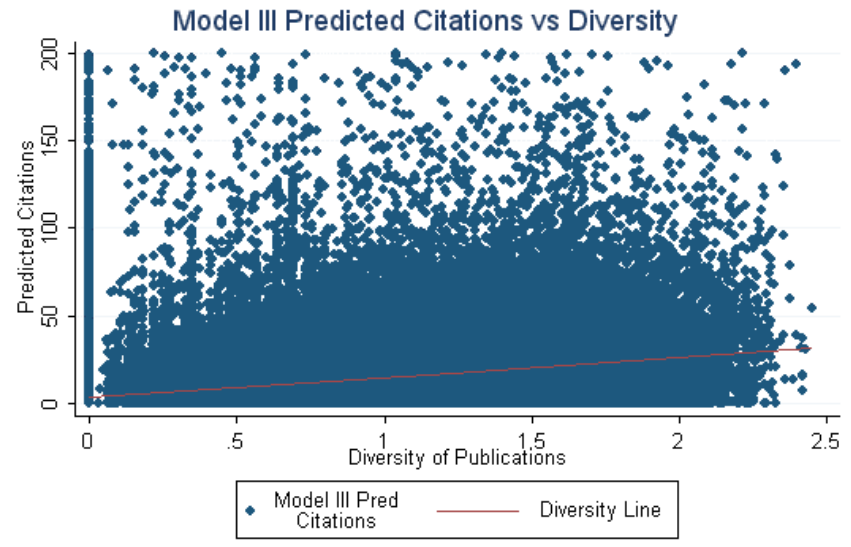




\section{Exhibit 9: Optimal Distance from Core of Cluster}

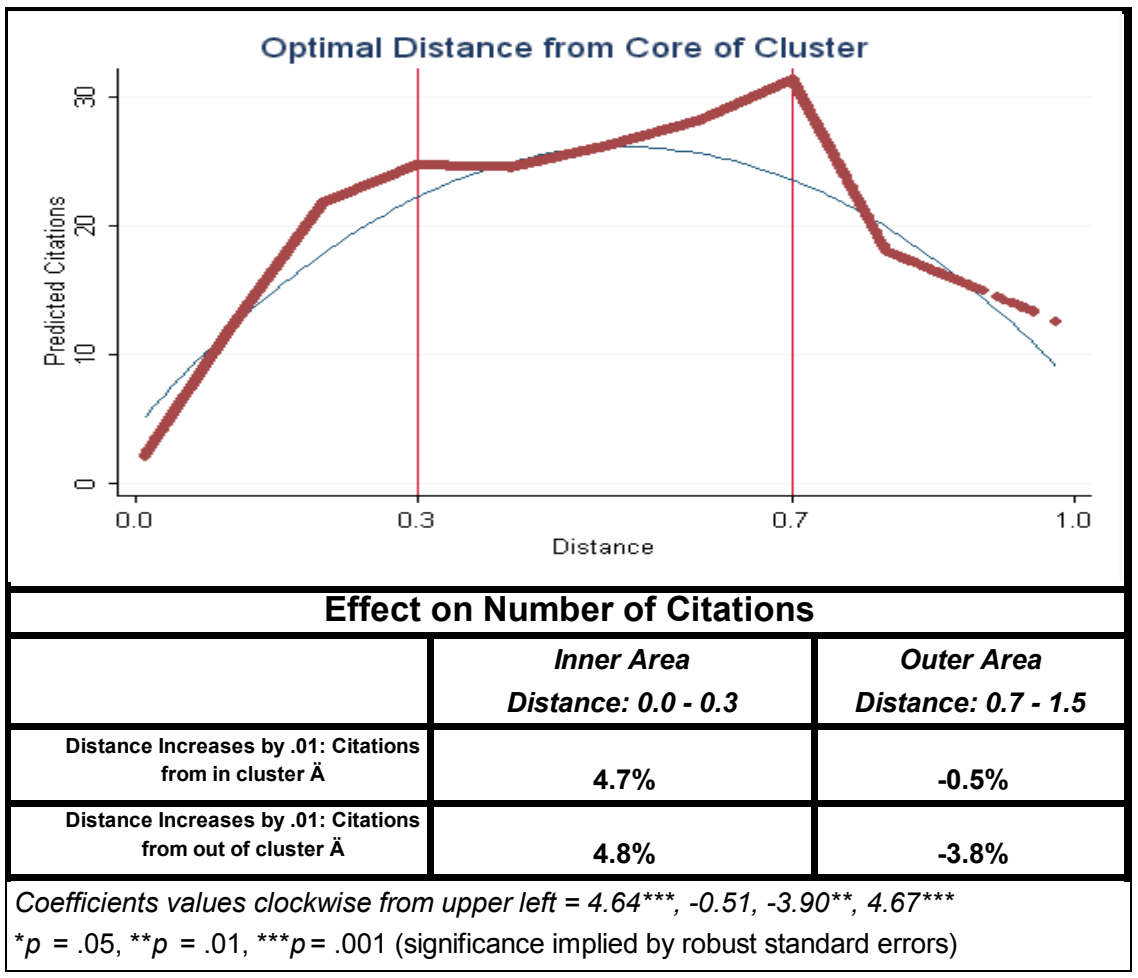

For regressions for the upper right and the lower right quadrant boxes above we used a standard negative binomial regression because the zero count was not influential enough to warrant a zero-inflated model. For the upper left and lower left quadrant regressions there were substantial zero counts so we used a zero-inflated NB model. The distance coefficient reported is only for the NB portion.

Table 6: Author Expected Citations and Cluster Diversity

\begin{tabular}{|c|c|c|}
\hline $\begin{array}{c}\text { Model III - Expected } \\
\text { Citations percentile }\end{array}$ & $\begin{array}{c}\text { NB coeff. for } \\
\text { diversity }\end{array}$ & $\begin{array}{c}\text { Zero Inflation } \\
\text { coeff. for diversity }\end{array}$ \\
\hline $\mathbf{1 0 0 \%}$ (full) & $0.164 * * *$ & $-0.719 * * *$ \\
\hline$<\mathbf{5 0 \%}$ (lower half) & $-0.057 *$ & $0.453 * * *$ \\
\hline$>\mathbf{5 0 \%}$ (upper half) & $0.583 * * *$ & $-.273 * * *$ \\
\hline$>\mathbf{9 0 \%}$ (top ten percent) & -0.065 (n.s.) & -0.016 (n.s.) \\
\hline
\end{tabular}

${ }^{*} p<.05, * * * p<.001$ 